Article

\title{
An Integral Approach to Sustainable Decision-Making within Maritime Spatial Planning-A DSC for the Planning of Anchorages on the Island of Šolta, Croatia
}

\author{
Nikša Jajac *, Jelena Kilić and Katarina Rogulj \\ Faculty of Civil Engineering, Architecture and Geodesy, University of Split, Matice hrvatske 15, 21000 Split, \\ Croatia; jkilic@gradst.hr (J.K.); kr0051@gradst.hr (K.R.) \\ * Correspondence: niksa.jajac@gradst.hr; Tel.: +385-(0)21-303-409
}

Received: 13 November 2018; Accepted: 20 December 2018; Published: 25 December 2018

check for updates

\begin{abstract}
The planning of nautical tourism development and especially, the planning of its supporting infrastructure development, is important topic of the maritime spatial planning. The focus of research is the integration of multicriteria analysis and stakeholders within concept modeling that will provide support to the spatial planning specialists in the design of plans related to the development of anchorage capacities for small vessels. It examines economic, environmental, ecological, social, and civil engineering concerns related to the use of coastal water. It is a complex and ill-defined civil engineering problem because of multiple stakeholders with diverse interests, numerous conflicting goals and criteria, huge quantities of information and data, limited resources, etc. The research is concentrated on an integral approach to sustainable decision-making within maritime spatial planning by the modeling decision support concept to the processes of identification, validation, comparison, and the selection of locations for anchorage construction, based on multicriteria methods, goal analysis, and the logic of the decision support system. The concept is tested on the island of Šolta, Croatia, and has been proven as being an applicable, consistent, efficient, and effective methodology for the planning of the anchorage locations.
\end{abstract}

Keywords: decision support concept; maritime spatial planning; multicriteria methods; anchorage location; stakeholders

\section{Introduction}

The encouragement for this research was primarily derived from the Directive 2014/89/EU of the European Parliament and the Council [1] from 23 July 2014, which establishes a framework for maritime spatial planning (MSP) in the EU. This Directive should help Member States develop maritime spatial plans to better coordinate the various activities on the sea in an efficient and sustainable way [2]. Croatia, although being extremely maritime country, still has no complete legal framework for setting up MSP [3,4]. In addition to the abovementioned, this research was intended to form an approach that will be functional and that will enable sustainable and inclusive decision-making in the planning of anchorage locations, as one of the components of MSP. To deal with such a complex process, and resulting in broad document, this research is focused only on anchorages as one of its many components. The proposed approach is related to supporting-planning processes, and to the deriving of such a specific plan that can be demonstrated and tested, and that can easily be adapted and applied to other components of MSP.

MSP has become a subject of considerable interest for the maritime countries in the recent years [5-7]. It is a process of analyzing and organizing temporal and spatial human activities 
in the marine environment to achieve ecological, economic, and social objectives [1]. Managing human activities to improve their usage and to reduce conflicts among usage, as well as to reduce conflicts between human activities and nature in a sustainable manner, are important outcomes of MSP. Comprehensively it can be said that the main outcome of MSP should be sustainable marine development [7].

Managing maritime areas, with the reconciliation of discordant needs of protecting their ecological balance and exploiting their natural resources, requires adequate policies and the integration of various sectoral approaches and interests in a coherent set of measures. An integrated approach is needed, because it allows for an effective and efficient coordination of the various authorities involved in coastal-related decision-making. MSP is a participatory process that includes all relevant parties and stakeholders as early as possible. It is very important to involve all relevant stakeholders, including coastal regions, at the earliest possible stage in the planning process, in order to achieve broad acceptance and support for implementation. Stakeholders' involvement means not only the involvement of maritime sectors or representatives of certain maritime activities, but also includes the general public, Non-Governmental Organizations (NGOs), and anybody who might be concerned or have an interest in the development of a given coastal region. They are an important source of knowledge, which can significantly raise the quality of MSP. Local and regional knowledge is important for incorporation into a MSP process, and might be only available via the people that live for generations in the same area. It is considered important to define the roles and responsibilities, and to strengthen interaction, not only between policymakers and stakeholders, but also between stakeholders' groups. The whole process is lengthened, depending on the broadness of the stakeholders' participation, and for this reason, it is essential to design a MSP process in a way that allows for enough time, and that plans ahead for iterative stakeholders' involvement. Depending on the challenge complexity that has to be taken on during a MSP process, it might be effective to plan for multiple stakeholder involvement stages, allowing for an extensive exchange of opinions and discussion of the issues involved [8]. Croatia participated in the creation of a pilot project Adriplan [9], but it still has not created its own MSP. Traditionally, the decision-making (DM) process for the management of coastal water resources is based on the experiences and opinions of the inner circle of stakeholders that are predominantly consisting of governmental representatives who generally have only specific knowledge and skills related to the analyzed problem. Thus, for example, scientific knowledge is still largely excluded from it [10]. One of the principal factors missing in the complex DM process is the co-operation between decision makers and the scientists, as well as the scientist between themselves. To make this cooperation effective and successfully implemented, scientists should negotiate to decide which research, monitoring, and technical tools should be used as a basis for policy making and management within the European context [11].

A response to setting requirements is the decision support system (DSS), which integrates the database, the model-base, and knowledge base consisting of various mathematical and analytical models that are used to analyze the complex data, thereby producing the required information [12]. The most important advantages of DSS are the inclusion of large amounts of data that represent one or more objectives and benefits, the incorporation of various stakeholders' groups such are local and/or regional government as the final decision makers, NGOs, scientific institutions, various experts dealing with coastal issues and local habitants, and comparison of the their ideas involved in the DM process, helping people to understand the impact of different types of management on civil engineering, ecologic, economic, and social objectives in a simple and user-friendly way, and bringing a compromise of solutions between possible management scenarios [13].

\subsection{Research Focus}

This research is concentrated on the DSC development in the planning of anchorage locations that will be implemented in MSP in Croatia. Although Croatia has no national maritime spatial plan, the entire territory of the Republic of Croatia is covered by various spatial plans, which 
include both terrestrial and marine areas (especially at the local/sub-national level). The planning of nautical tourism development and especially the planning of its supporting infrastructure (such as anchorages) development are important topics when MSP is conducted. According to the Regulation of classification and categorization of nautical tourism ports [14], the anchorage is defined as a part of the water space that is equipped with accoutrements for vessels mooring in a bay that is protected from the storm. Anchorages for smaller vessels have been considered in detail as being acceptable locations for boat residence, primarily along the coastal zone of the Central Dalmatia islands, which are in the spatial scope of the survey.

Considering geographic characteristics and socio-cultural implications, the Mediterranean is among the most important areas of nautical tourism in the world. Croatia is a Mediterranean country, and it has an indented coastline and an insular archipelago with more than a thousand islands. Just because of these natural resources, Croatia represents a significant place in the development of nautical tourism. Despite the current developmental achievements, Croatian nautical tourism in many elements of the offer has not reached the level of natural and historical heritage value as well as the development of spatial possibilities, and nautical tourism has not yet used all of its development potential [15]. One of the biggest disadvantages of nautical tourism in Croatia is the insufficient number of berths. The demand is larger than the offer, including the demand for a permanent berths, but also transit season berths [16]. According to the information of the Institute for Tourism from 2015, Croatian nautical tourism has about 17,000 berths for boats and yachts. The Strategy for Nautical Tourism Development [15] clearly perceives the current weak development of Croatia in relation to other Mediterranean countries. The share of the Croatian coast in the total coastline of the Mediterranean is $12.2 \%$ of the shore coastline and $33 \%$ of the island coastline, but in the offer of berths, Croatia's share in the Mediterranean is only $6.9 \%$. From the presented statistical data, it can be clearly noted that there is a great need, and also the pressure to build berths of all types. According to the Tourism Development Strategy of the Republic of Croatia until 2020, construction of 15,000 new berths is planned; 5000 berths in ports of nautical tourism, 5000 in existing ports open to public transport, and 5000 berths on the shore. New development will involve the application of new technologies and environmental standards, taking into consideration all relevant ecological criteria [17].

The share of the SDC in the total capacity of the berths in Croatia according to the spatial plans is $12 \%$ for the berths on the sea and $9 \%$ for the berths on the shore, which is significantly below the available capacities compared to the northern coastal counties in Croatia [16]. According to the spatial plan of the Split-Dalmatia County, the planned growth of the total berth capacity is expected to be more than $150 \%$. For this reason, there was a need for systematic planning and sustainable decision-making when it comes to the construction of anchorages. Because of that, there was a need for suggesting an approach/concept that will support decision makers and policy makers in dealing with this delicate problem. The main goal of the research is to design a model of decision support concept (DSC), in combination with the multicriteria analysis and methods, as an approach that will provide qualitative and sustainable decision-making within maritime spatial planning when it comes to the construction of anchorage locations. The concept of decision support in combination with multicriteria analysis and methods is used in order to support the decision makers in very complex and ill-structured problems, and is used for the majority of decisions of any value. It is used instead of other decision-making techniques, because of its fundamental simplicity, its easily applicability across decisions of this type (planning of anchorage locations), and its ease in increasing or decreasing its complexity to match the value of the decision to be made. This technique easily captures the knowledge from a decision, and makes it reusable for others making the same or similar decisions. Also, it was found to be an easily applicable decision-making technique among stakeholders who are identified as being relevant for this type of problem, because, by their opinion, they have found it to be the most comprehensible and the most systematic approach for decision-making.

The approach of the decision-support concept is timely and important, considering the implementation of MSP. It is useful in MSP and coastal water management, because of its flexibility 
and adaptability, and it significantly contributes to the quality of decision-making efficiency toward the planning of anchorage locations. It can easily be implicated to other marine and nautical installations, with minor adjustments. It enables institutions and organizations such as local and regional government to recognize the concept as being relevant to inform policies and local initiatives to address regulative, normative, and cultural-cognitive dimensions of institutions in the various aspects of MSP.

The need for the establishment of a systemic approach for the development of the spatial plan is especially present in attractive areas for the development of nautical tourism such as the south of Croatia, more precisely the Split-Dalmatia County (SDC). It is situated on the Adriatic coast, and characterized by an indented coastline and numerous islands, but also with the rapid development of tourism. The SDC (which, with its islands, makes the narrower scope of this survey) does not have enough anchorages in relation to increasing demand, and so exploring the possibilities of sustainable planning on the establishment of the spatial plan for anchorages while respecting the space requirements (functional and socio-economic organization with quality fulfillment of cultural, civil engineering and environmental conditions) stands out as a relevant problem for research. An analysis of the condition on the field was made within the validation area, which in this case, is the island of Šolta as one of the potential locations for the construction of berths.

\subsection{Literature Review}

In recent years, DSS has found its application in the MSP. Pınarbaşı et al. [18] analyzed the present use of the decision support (DS) in MSP by analyzing 28 examples of different countries. Most of the examined MSP reports did not explicitly state the application of decision support, but it can be concluded that in majority of cases, it was applied in the first phases of the MSP process where DS were used for gathering data, defining the current situation and the identification of issues, constraints, and future conditions. This can be coped with the fact that most countries have just started to apply MSP. The application of DS in MSP has been found in papers dealing with the protection of environment, ecology, biodiversity, coastal, and seabed habitat features [19-26], marine traffic [27-36], anchorage planning strategy [37], and site identification (selection) [38-40]. It can be concluded that most of the papers, in which DSS is used in the planning of various activities in MSP, are based on ecological issues, and on the issue of regulating traffic within maritime industrial ports, but not with the development of spatial plans, and especially not with plans related to the construction of anchorages as a civil engineering problem. Given that tourism in Croatia is a main economic activity, and with the above-mentioned facts that none of the prior studies have been concerned with the priority ranking of anchorage construction, taking into account economic, sociological, and ecological aspects, and all intentions of nautical tourism development, based on a scientific approach, the motive for this research has been derived. The aim is to design a decision support concept (DSC) in combination with multicritera analysis and methods, while planning the establishment of spatial plan for anchorages construction on a wider coastal area, based on nautical tourism factors and needs. The implementation of spatial plans as a regulator of natural, historical, and cultural heritage, ecosystem, and workplaces need to be protected, but also with it, the safety of sailing in the conditions of ever-increasing tourist burden on the entire coast of the island needs to be improved. All of this is characterized by a large number of spatial and other data and information, a large number of stakeholders, determinants derived from strategies, as well as social needs that also fall within the nature protection activities. The interaction of stakeholders with different needs, as well as different levels of background knowledge on the issue, is a great challenge for the purpose of defining a concept that will be objective in one hand, but which will successfully meet the requirements set on the other hand. 


\section{Materials and Methods}

This research is based on the modeling of DSC to enable the inclusion of multiple stakeholders with their different preferences and knowledge, as well as to enable the mitigation of the conflicts between stakeholders and their activities on the one hand, and the conflicts between human activities and nature on the other hand, making it easier to design and implement the planning of anchorages. In this section, the proposed DSC to design spatial planning related to the development of anchorage capacities in terms of its architecture is described, and afterwards, its functionality, i.e., application. The concept of DSC is based on the logic of DSS for urban infrastructure engagement [41]. Multicriteria analysis and multicriteria methods such as the Analytic Hierarchy Process (AHP) [42,43] and the Preference Ranking Organization Method for Enrichment Evaluation (PROMETHEE) II, V [44-47] are used. These methods can provide an interactive approach, which is especially important for dealing with numerous stakeholders and group DM.

This strategic kind of problem that requires comprehensive analysis needs the establishment of a management system, and DM related to it. Similar studies to this one, but at the same time significantly different, were given by Jajac et al. [48], in which specific DSC is used for the selection of historic bridge rehabilitation method, and by Bitunjac et al. [49], where DSC is used for the sustainable management of a bottom trawl fleet.

\subsection{Multicriteria Analysis and Multicriteria Methods}

As the problem of establishing spatial plans for anchorage construction is complex and socially sensitive, and is characterized by a large number of spatial and other data and information, a large number of stakeholders and criteria that need to be considered, a multicriteria analysis and methods are chosen as being most appropriate tool for dealing with this kind of issues. Multicriteria analysis establishes preferences between anchorage locations to a set of objectives that the experts and stakeholders have identified, and for which they have established measurable criteria to assess the extent to which the objectives can be achieved. In simple circumstances, the process of identifying objectives and criteria may alone provide enough information for decision-makers.

\subsubsection{Analytic Hierarchy Process}

The AHP is suitable for dealing with complex problems that are related to a choice-making among several alternatives, and providing their comparison. It is useful in multicriteria decision making, with wide applications in many areas of science and practice. It is a tool for multi-criteria group decision making, which analyzes the decision-making problem displayed in different levels of the hierarchy. It is based on the subdivision of the problem in a hierarchical form, and each level represents different factors (economical, technical, social, etc.) as evaluated by experts. Four basic steps of the AHP method are [42]:

- Hierarchical structure modelling. The hierarchy consists of objectives, variety of criteria, and alternatives at the lowest level. The main goal of decision-making is presented at the highest level of the hierarchy. The objectives that support the main goal are at the intermediate level, and the criteria that influence the decision are presented at the last level.

- Comparison matrix definition. The comparison matrix of elements of each hierarchy level is constructed by using individual comparisons translated into scale values. The preferences of decision makers are quantified by using Saaty's nine-point scale [41].

- Priority determination. Pair-wise comparison generates a matrix of the relative rankings for each level of the hierarchy. The number of the matrix depends on the number of elements in each level. After all matrices have been created, the vector of relative weight and maximum eigenvalue $\left(\lambda_{\max }\right)$ for each matrix is calculated.

- Consistency index and ratio calculation. The validity of comparisons can be evaluated through the consistency ratio for which the calculation a consistency index (CI) of a $n \times n$ matrix is needed. 
It is defined as the ratio $\mathrm{CI}=\left(\lambda_{\max }-n\right) /(n-1) \cdot \lambda_{\max }$ is maximum eigenvalue of the matrix, and $n$ is the matrix dimension. The consistency ratio (CR) is calculated as CR $=\mathrm{CI} / \mathrm{RI}$, where the RI value is the random consistency index. The acceptable value of the $C R$ depends on the matrix size $(0.1$ for matrices $n \geq 5)$. If the $C R$ value is equal to or less than the specified value, than the evaluation within the matrix is allowable and close to ideal values, and the evaluation process does not need to be improved in a joint meeting of the research participators.

\subsubsection{Preference Ranking Organization Method for Enrichment Evaluation}

The PROMETHEE method is well-accepted among decision-makers, because it is comprehensive and it has the ability to present results by using simple ranking [44]. It performs a comparison and ranking of various alternatives that are at the same time valued on the basis of several quantitative or qualitative criteria.

A matrix consisting of a set of potential alternatives $A$ is an input for the PROMETHEE method. Each $a$ element of $A$ is $f(a)$, which represents the evaluation of one criterion, and each evaluation $f_{i}$ $\left(a_{i}\right)$ must be a real number. The PROMETHEE I method gives the partial relation, and then, from the PROMETHEE II method, which ranks the actions by the complete ranking calculating net flow, a net outranking flow is obtained [46]:

$$
\Phi(\mathrm{a})=\Phi^{+}(\mathrm{a})-\Phi^{-}(\mathrm{a})
$$

$\Phi^{+}$(a) is the positive outranking flow, and is defined as:

$$
\Phi^{+}(\mathrm{a})=\frac{1}{n-1} \sum_{x \in A} \prod(a, x)
$$

and $\Phi^{-}($a) is the negative outranking flow, defined as:

$$
\Phi^{-}(\mathrm{a})=\frac{1}{n-1} \sum_{x \in A} \prod(x, a)
$$

where $a$ and $x$ are the actions from the set of actions $A$ (during the pair wise comparison of action $a$ with all other $n-1$ actions), $n$ represents the number of actions, and $\Pi$ is the preference index that is defined for each pair of actions:

$$
\prod(a, b)=\frac{\sum_{j=1}^{m} w_{j} P_{j}(a, b)}{\sum_{j=1}^{m} w_{j}}
$$

where $P_{j}(a, b)$ represents preference of $a$ over $b$ for a given preference function of criterion $j$, and $w_{j}$ is a weight of criterion $j$. Since $\sum_{j=1}^{m} w_{j}=1$, Equation (4) changes its expression into: $\Pi(a, b)=\sum_{j=1}^{m} w_{j} P_{j}(a, b)$.

There are six types of preference functions proposed by the authors of the method $[45,46]$ : usual criterion, U-shape criterion, V-shape criterion, Level criterion, Linear criterion, and Gaussian criterion. The analyst and the decision-maker, in mutual agreement, choose one of the six functions for each criterion with regard to their knowledge about the intensity and direction of preference. In each particular case, some parameters should be determined in advance. Each of the parameters has a real economic meaning, and they are: parameter $q$ is the indifference threshold, parameter $p$ is preference threshold, and parameter $\sigma$ represents the Gaussian threshold.

Different sets of criteria weights can be used, and then each set represents one scenario. Experts and sometimes other stakeholders usually determine criteria weights. The resulting weight of each criterion can be perceived as the compromised weight that stands as a compromised view to the problem, as the view that respects different views of different stakeholders equally.

PROMETHEE I and II are appropriate for the selection of one alternative. However in some applications a subset of alternatives must be identified, given a set of constraints. PROMETHEE $V$ extends the PROMETHEE methods to that particular case [47]. 
Let $\left\{a_{i}, i=1,2, \ldots, n\right\}$ be the set of possible alternatives, and the following Boolean variables are associated to them:

$$
x_{i}= \begin{cases}1 & \text { if } a_{i} \text { is selected }, \\ 0 & \text { if not }\end{cases}
$$

The PROMETHEE V procedure consists of the two following two steps:

Step 1: The multicriteria problem is first considered without constraints. The PROMETHEE II ranking is obtained, for which the net flows $\left\{\phi\left(a_{i}\right), i=1,2, \ldots, n\right\}$ have been computed.

Step 2: The following $\{0,1\}$ linear program is then considered in order to take into account the additional constraints (provided that they can be expressed linearly).

$$
\begin{gathered}
\max \left\{\sum_{i=1}^{k} \varnothing\left(a_{i}\right) x_{i}\right\} \\
\sum_{i=1}^{n} \lambda_{p, i} x_{i} \sim \beta_{p} \quad p=1,2, \ldots, P \\
x_{i} \in\{0,1\} \quad i=1, \ldots, n
\end{gathered}
$$

where $\sim$ holds for $=, \geq$ or $\leq$, and where $\lambda_{p, i}$ are the coefficients of the constraints. The coefficients of the objective function (6) are the net outranking flows. The higher the net flow, the better the alternative. The purpose of the $\{0,1\}$ linear program is to select alternatives, collecting as much net flow as possible, and taking the constraints into account. The constraints (7) can include cardinality, budget, return, investment, marketing, etc. They can be related to all of the alternatives, or possibly to some clusters. After having solved the $\{0,1\}$ linear program, a subset of alternatives satisfying the constraints and providing as much net flow as possible is obtained [47].

\subsection{Decision Support Concept for the Planning of Anchorages}

Figure 1 shows architecture of the proposed DSC. This approach of the design of DSC is preferred by the authors, because of their own experience with similar methodological approaches, but also because of the research of other authors [50-53]. Of course, it is an overview of the proposed methodology that consists of several phases, while each phase is a method for itself. The presented methodology is not intended for direct implementation/use by policy makers, but with support of a methodologist specialist.

The concept begins with the analysis of the MSP project settings. In this step, the current situation within the research area is analyzed by nautical and anchorage experts, and local and regional self-government, which includes analysis of the research area, analysis of existing strategies and action plans, and European and Croatian laws and regulations, as well as an analysis of project components and relevant impacts that are essential for the development of nautical tourism with anchorage capacities growth. The next step is the identification and organization of relevant stakeholders (and their representatives). For the purpose of this research, to avoid the influence of "individual authorities", the division of selected stakeholders into three relevant groups was provided. This division was important, not just to avoid authority influence, but also to evade one group that might lead to the domination of experts of particular areas in generating criteria that apply to those areas. These groups are:

1. Nautical and anchorage experts (experts for all aspects related to nautical matters and anchorages that cover civil engineering, economic, cultural, and ecological components)—four researchers from the University of Split,

2. Representatives of local and regional government-four government representatives (three from the Split-Dalmatia County, and one from the Local Self-Government Unit of the Šolta municipality), 
3. Users' representatives of the anchorage space-four users' representatives (two representatives from the representative body in the municipality of the Šolta-one ruling and one opposition, and two representatives of the concessionaires).

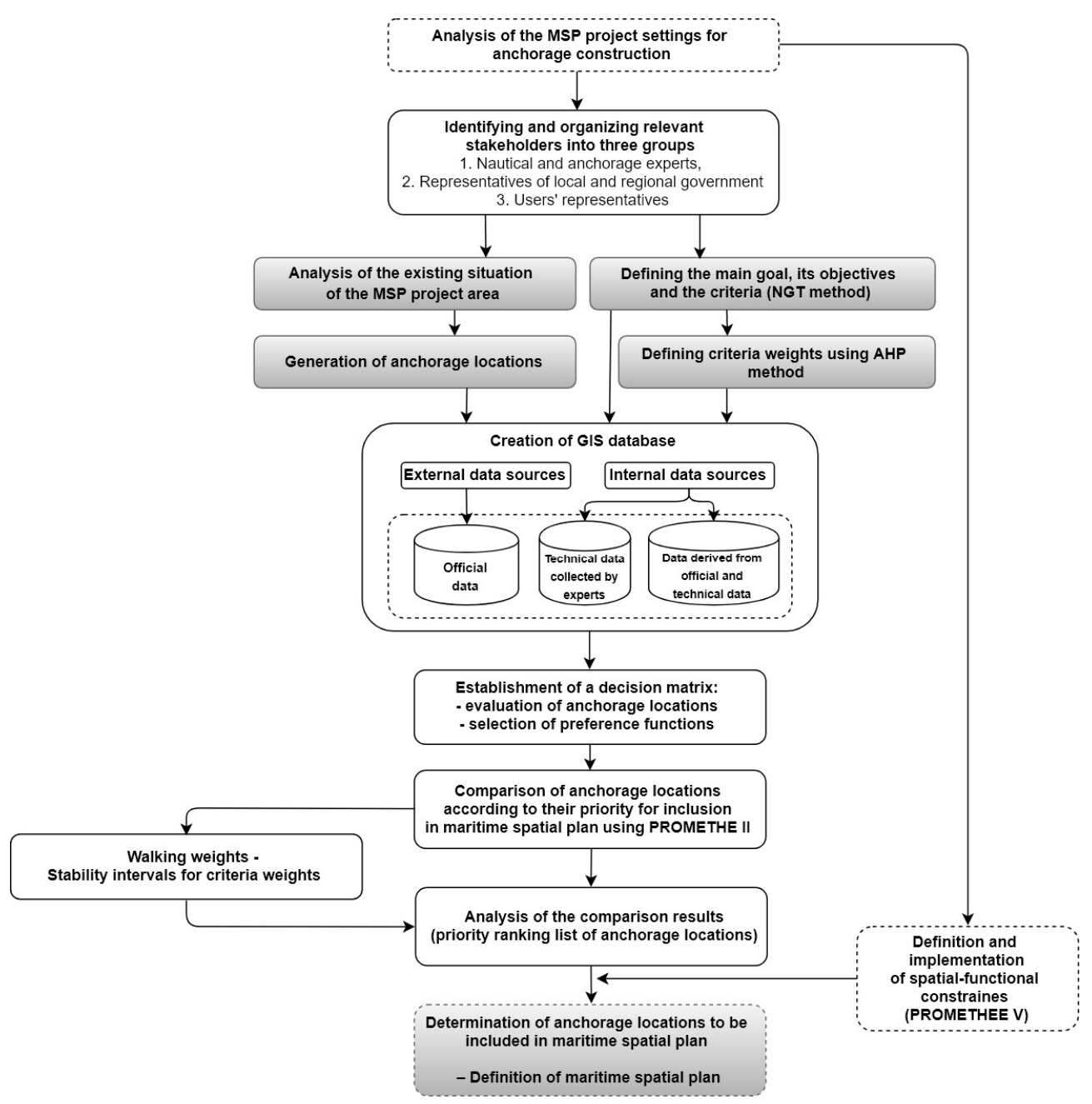

Figure 1. Application of the decision support concept (DSC) to a spatial plan design related to the development of anchorage capacities with a stakeholders activity legend.

Their involvement is very important for increasing the transparency of the planning process, and to timely acquaint themselves with future activities that are related to anchorage construction planning. The task of the group's representatives is to convey the opinions of the stakeholder group that they represent. Within Figure 2, the activities of all stakeholders are rounded with solid lines and grey-colored; the activities of the nautical and anchorage experts, together with the local and regional government, are rounded with broken lines and they are not colored; the activities of the DSC methodology expert and the nautical and anchorage experts are rounded with solid lines, and they are not colored; the activities of the local and regional governments are grey colored and rounded with broken lines.

In the next step, all identified, selected, and grouped stakeholders simultaneously performed two activities. The first activity was the analysis of the existing situation of the MSP project area. The parallel activity to previous one is design of a goal hierarchy structure (GHS) consisting of the main goal, its objectives, and the criteria. The establishment of a GHS in a form of a goal tree provides a better understanding of the interrelationships between the main goals and the objectives, and between the objectives and their criteria, thus ensuring a higher quality of the objective generation process [49]. 


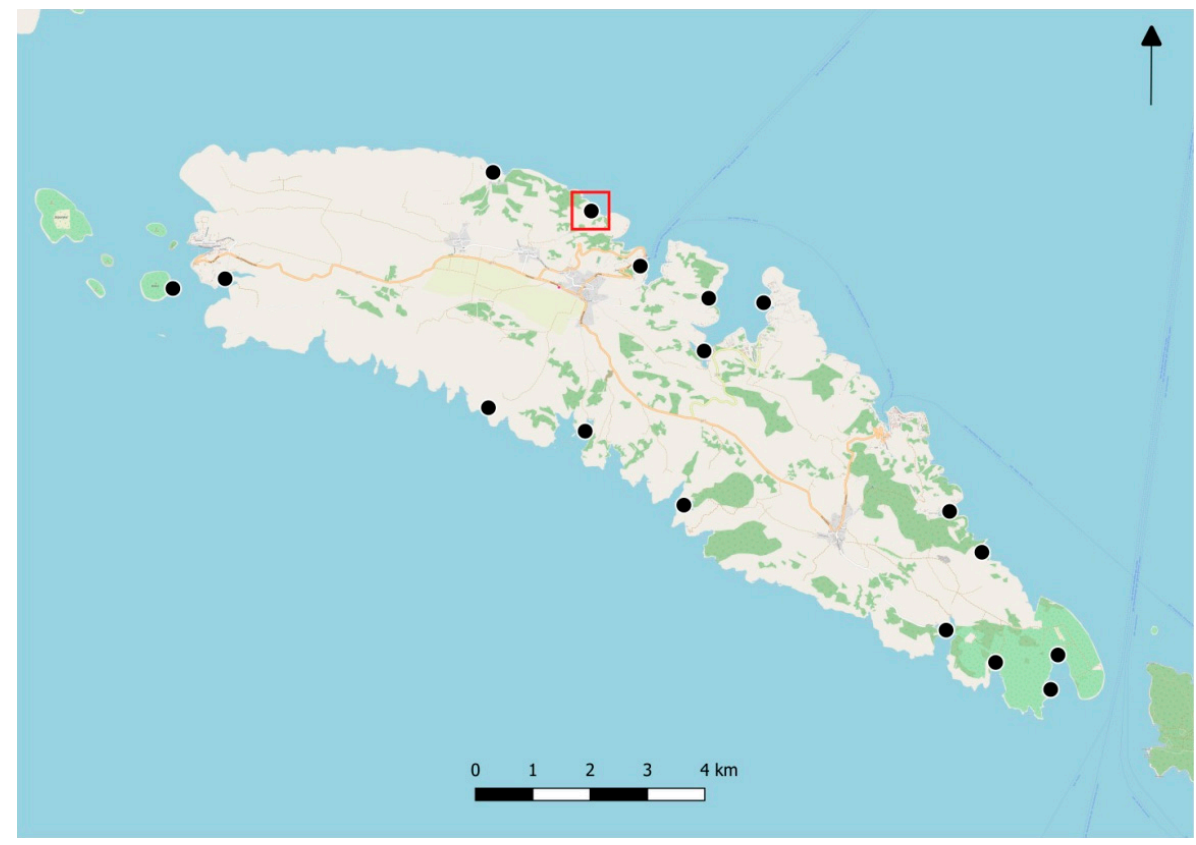

Figure 2. Island of Šolta and the identified anchorage locations.

Stakeholder relations are not static; they are dynamic and in a constant state of flux. Their attitudes and actions may change at different stages. This reflects the dynamic nature of the relationship between stakeholders, and for that reason, to establish a GHS, a brainstorming and nominal group technique (NGT) were used. The brainstorming technique was approached at the very beginning of the DM process, and the problem and achievement of the main goal were intentionally discussed among the members of each group. This technique enables the free creation of ideas, in which group members generate variants of problem-solving, regardless of whether they are realistic or practically feasible. The NGT was given the advantage for further stages of the DM process. The NGT enables the assimilation of ideas and judgment of knowledgeable individuals toward building a group consensus for a desired outcome [54]. The members of each group generated ideas separately and anonymously, without input from others, by writing them down on paper. At the end of the session, the pieces of paper were merged together to produce a set of ideas from the group.

Selected stakeholders are experts in the field of coastal management; among them there are those from scientific institutions, as well as from companies dealing with coastal engineering and management. The mentioned stakeholders in defining a GHS have mutually exchanged their knowledge in the areas of economic activities, ecosystem services, and boats anchoring, which are extremely important for the problem of planning the priority construction of anchorages. In doing so, the most significant effort of the stakeholders involved in the decision-making process has been invested in the establishment of a GHS, because of the often conflicting attitudes arising from different views on the same issue. The establishment of a GHS involved finding the optimal form of interaction between the economic activities, ecosystem services, and boat anchoring. Differences in preferences and the background knowledge of stakeholders are included through the process of assigning weights to all levels of a GHS.

The NGT was used for generating the GHS in the following steps [55]:

(1) Each of the groups' members wrote down the criteria by which the main goal had to be carried out.

(2) Each member wrote down his or her criteria established during brainstorming, but did not discuss them. The group's representative recorded all the criteria prepared by the members.

(3) The representative asked each team member to explain his or her criteria. 
(4) The representative asked each member to write down the criteria that seemed especially significant, and then recorded the number of people who believed each criterion to be a priority.

(5) Members rated each of the criterion from no importance (0) to top priority (10).

(6) The representative then collected and added the ratings, and recorded the cumulative rating for each of the criteria. The outcome of the NGT process was the list of objectives and criteria for each stakeholder's group. These objectives and criteria were then adopted in the GHS in the form of a goal tree.

At the top of hierarchy is the main goal, and it is divided into several supporting objectives. These objectives (creating last level of GHS) are determined and adopted as a criteria at a time when stakeholders have reached a consensus about their relevance and measurability (they agree that objectives are measurable enough, meaning that their achievement can be assessed with sufficient quality). While dividing each objective into criteria, it must be emphasized that a certain group of stakeholders is put in charge, only when defining criteria that are related to their expertise, but even then, each proposed criterion can be adopted in GHS only if it is confirmed and accepted by all stakeholders. At the same time, because of the criteria whose scopes are overlapping, representatives of other groups are tasked with organizing the objectives and criteria to eliminate their duplication according to their aims and scopes.

Next, two parallel activities are the generation of anchorage locations and the definition of criteria weights (using AHP). As the research subject is the modeling of the concept that will provide a holistic approach to all potential anchorage locations within the analyzed area, only those locations that met the minimum of all conditions (preconditions determined by the aim and scope of the determined criteria, and/or derived from legislative acts, higher level plans and strategies etc.) can be selected to be included in a set of alternative anchorage locations. All stakeholders are involved in this process, as well as in the process of the criteria weights (importance) determination. Due to the expected inequality of the criteria importance, their weights are determined first as the sets of weights that are defined by a particular group of stakeholders (weighting scenarios), and then as compromise weights (compromised scenario) derived by the arithmetic mean. This approach provides the environment of $\mathrm{DM}$ for criteria weights in which all groups of stakeholders are equally respected.

The next step is the creation of the GIS database. In defining this and the next three steps of the DSC methodology, expert and nautical and anchorage experts are involved. The database consists of:

- external data that includes official data from public sources and several SD County departments, several firms owned and managed by SD County and from national governmental institutions; internal data that includes technical and other data related to anchorage design requirements, and information derived by from the data of local and national governmental institutions.

The following step is a decision matrix formation that includes the evaluation of all alternative anchorage locations according to all criteria, with respect to the defined assessment techniques of each criterion, and the selection of preference functions. The characteristics that are essential for forming preferences, when comparing locations according to a particular criterion, are the identification of whether the problem is a minimum or a maximum, as well as the selection of the adequate shape of the preference function for each criterion. After that, PROMETHEE II is conducted for the comparison of the anchorage locations according to their priority for inclusion in the maritime spatial plan. A very important step is the weight sensitivity analysis, which gives information on the stability of the obtained ranking list, due to changes in the defined criteria weights. By analyzing the results, it is possible to determine the relative relation between individual locations, which gives a better overall insight into the analyzed issue. Besides that mentioned, and by taking into account the strategies and plans of higher-order and legislative acts, important influences on the creation of the plan can be determined. Because of that, it is necessary to define and introduce several constrains that can cover all other relevant influences like those related to social-natural protection, cultural heritage issues, and techno-economic aspects of such a problem, ensuring the spatial-functional development 
of nautical tourism within the analyzed area. The defined constraints from nautical and anchorage experts and from local and regional governments are introduced by using the PROMETHEE V method. The result of applying this method is the set of proposed anchorage locations to be included in MSP. The result represents a solid base for final DM by local and regional government representatives. Also, it is important to notice that the presented approach is applicable to already existing MSP, if anyone wants to amend/refresh it, as well as to any other MSP components. In this case it is only necessary to modify the elements at the lowest GHS level to define criteria that accurately match the defined problem. It is also possible to add new or expose existing criteria, but it is especially important that these decisions are provided in the same way as in this process, by involving all relevant stakeholders.

\subsection{Generation of Anchorage Locations}

Šolta appertains to the group of the most indented islands, with a coastline of $93.1 \mathrm{~km}$, and with the characteristics of large and deep coves and bays. An important element of the island position is its participation in the Adriatic developmental backbone, the proximity of the macro-regional center (the town of Split), its site in the Split developmental center, and at the same time, a suitable space for the internationalization of development programs. A significant element of the position is its immediate participation in important and very frequent internal and international waterways, in particular, the Split Gate [56]. The shapes and characteristics of the coast, coves and bays, and the windy climate, determine the possibility of securing ports for maritime traffic, and anchorages for smaller vessels, as well as parts of the coastline for mooring vessels.

The DSC realization started with an analysis of the MSP project settings for exact project area of the island of Šolta. This activity is followed by identification and gathering together of relevant stakeholders (and their representatives). Three groups of stakeholders were involved in the DM process, as mentioned in previous section.

For the purpose of the proposed concept validation, the locations on the island of Šolta were obtained from the following sources Galasso, et al. [57] and Favro, et al. [15]. By analyzing the scope of the survey according to their convenience of anchoring and the proximity of attractive locations, 17 preliminary anchorage locations were identified, as shown in Figure 2 below.

After the initial selection of these locations, a detailed analysis of their technical properties were performed. Accordingly, from the initial collection of data, it is necessary to eliminate those locations where, due to natural (environmental protection), historic (protection of cultural heritage), and technical attributes (legal regulations), anchorages cannot be built. Unsuccessful positions for anchorage construction were determined in Dražetina cove on the north side of the island, due to an underwater power cable (in square in Figure 2). Placing the anchorage on such a location would be a violation of the legal regulations. It is important to emphasize the differences between the areas in the navigational maps and the areas that will be included in the maritime spatial plan. Namely, the information that can be obtained from the navigational maps for the analyzed area has been taken as the criteria for their evaluation, but they are not the only evaluation criteria, as will be presented in the hierarchical structure of the objectives. Specifically, the criteria also includes social, technical-economic, and natural protection, and cultural heritage aspects of the problem, which provide an integral approach for planning.

The research was conducted on the basis of 16 preliminary locations, of which nine are located on the southern coast of the island, and seven are located on the northern coast. For each preliminary location, three types of variant solutions have been foreseen, that differ according to the size of the anchorage area and the number of vessels that it can receive (Figure 3). Variant solutions were determined in a manner such that the area of the first solution for each analyzed location (bay or cove), i.e., N11 on Figure 3, is derived as the 50\% reduced area of the second solution (N12 on Figure 3), while the area of the third solution (N13 on Figure 3) is derived as the $50 \%$ increased area of the second solution. In cases where the third solution exceeded the maximum permissible area for the anchorage construction (by restrictions within, i.e., a legal act or another similar document/directive), 
the second solution was decreased, and accordingly, the first solution in relation to the third solution that complied with the maximum allowed area of the future anchorage.
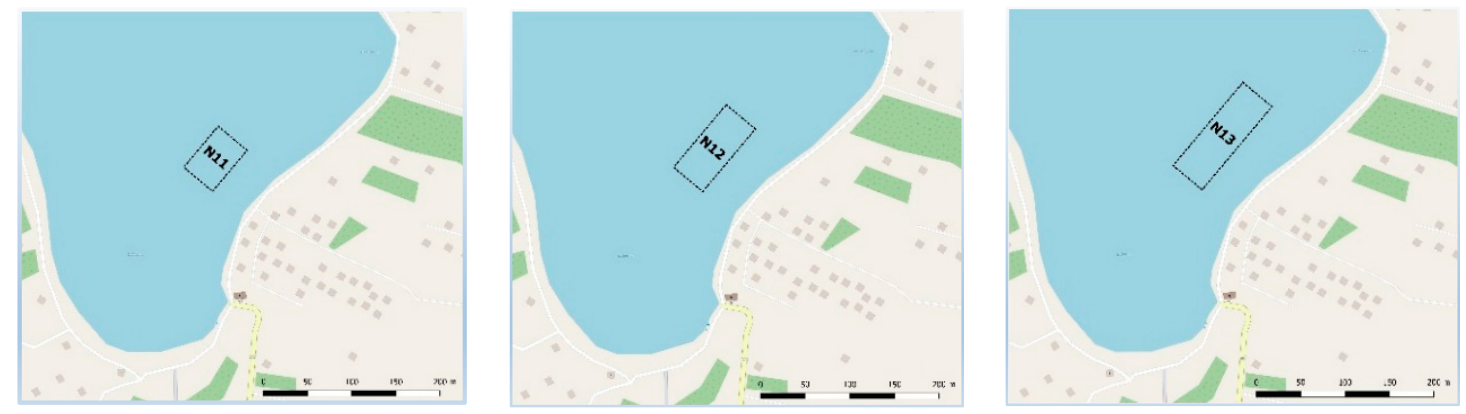

Figure 3. Variant solutions (N1i; i = 1, 2, 3) of anchorages according to their size (NB Nečujam).

The "same basis" for the different alternatives is ensured by the introduction of limitations related to the design requirements in the process of establishing the second solution at the same location. This must be in accordance with positive legal requirements and professional standards related to all relevant aspects of anchoring (social, techno-economic, cultural, and environmental aspects). Also it is based on local nautical and other related customs and traditions. Furthermore, it must be emphasized that when multicriterial analysis and particularly the MCDM method PROMETHEE are used, the previously mentioned "same basis" is something that is completely different. This is a fact, because this method and analysis take into account the relative interrelations and importance of the criteria, resulting in a specific process of preference establishment. In this approach, the "same basis" is ensured by the assessment of all alternatives according to the same set of criteria (each with the same assessment technique). Consequently, 48 alternative locations were generated as shown in Table 1 below.

Table 1. List of 48 identified alternative locations for anchorage construction on the island of Šolta (Northeast cove: NEC; North bay: NB; North cove: NC; West cove: WC; South cove: SC; Southeast cove: SHC; Southeast bay: SEB).

\begin{tabular}{|c|c|c|c|c|c|c|c|}
\hline ID & Locations & Anchor & Tag & ID & Locations & Anchor & Tag \\
\hline 1 & NHC G.Krušica & Gornja Krušica 1 & GK1 & 25 & WC Balkun & Balkun 1 & B1 \\
\hline 2 & NHC G.Krušica & Gornja Krušica 2 & GK2 & 26 & WC Balkun & Balkun 2 & B2 \\
\hline 3 & NHC G. Krušica & Gornja Krušica 3 & GK3 & 27 & WC Balkun & Balkun 3 & B3 \\
\hline 4 & NEC Vela luka & Vela luka 1 & VL1 & 28 & SC Tatinja & Tatinja 1 & $\mathrm{~T} 1$ \\
\hline 5 & NEC Vela luka & Vela luka 2 & VL2 & 29 & SC Tatinja & Tatinja 2 & T2 \\
\hline 6 & NEC Vela luka & Vela luka 3 & VL3 & 30 & SC Tatinja & Tatinja 3 & $\mathrm{~T} 3$ \\
\hline 7 & NB Nečujam 1 & Nečujam 11 & N11 & 31 & SC Senjska uvala & Senjska uvala 1 & SU1 \\
\hline 8 & NB Nečujam 1 & Nečujam 12 & N12 & 32 & SC Senjska uvala & Senjska uvala 2 & SU2 \\
\hline 9 & NB Nečujam 1 & Nečujam 13 & N13 & 33 & SC Senjska uvala & Senjska uvala 3 & SU3 \\
\hline 10 & NB Nečujam 2 & Nečujam 21 & N21 & 34 & SC Zaglav & Zaglav 1 & Z1 \\
\hline 11 & NB Nečujam 2 & Nečujam 22 & N22 & 35 & SC Zaglav & Zaglav 2 & $\mathrm{Z} 2$ \\
\hline 12 & NB Nečujam 2 & Nečujam 23 & N23 & 36 & SC Zaglav & Zaglav 3 & $\mathrm{Z3}$ \\
\hline 13 & NB Nečujam 3 & Nečujam 31 & N31 & 37 & SEC Vela travna & Vela travna 1 & VT1 \\
\hline 14 & NB Nečujam 3 & Nečujam 32 & N32 & 38 & SEC Vela travna & Vela travna 2 & VT2 \\
\hline 15 & NB Nečujam 3 & Nečujam 33 & N33 & 39 & SEC Vela travna & Vela travna 3 & VT3 \\
\hline 16 & $\begin{array}{c}\text { NC D. Krušica, } \\
\text { M. Krušica }\end{array}$ & $\begin{array}{l}\text { D. Krušica, } \\
\text { M. Krušica } 1\end{array}$ & DMK1 & 40 & SEB Livka-Motika & Livka-Motika 1 & LM1 \\
\hline 17 & $\begin{array}{l}\text { NC D.Krušica, } \\
\text { M. Krušica }\end{array}$ & $\begin{array}{l}\text { D. Krušica, } \\
\text { M. Krušica } 2\end{array}$ & DMK2 & 41 & SEB Livka-Motika & Livka-Motika 2 & LM2 \\
\hline 18 & $\begin{array}{c}\text { NC D. Krušica, } \\
\text { M. Krušica }\end{array}$ & $\begin{array}{l}\text { D. Krušica, } \\
\text { M. Krušica } 3\end{array}$ & DMK3 & 42 & SEB Livka-Motika & Livka-Motika 3 & LM3 \\
\hline 19 & NB Rogač & Bocanac, Kašjun 1 & BK1 & 43 & SEB Livka & Livka 1 & L1 \\
\hline 20 & NB Rogač & Bocanac, Kašjun 2 & BK2 & 44 & SEB Livka & Livka 2 & L2 \\
\hline 21 & NB Rogač & Bocanac, Kašjun 3 & BK3 & 45 & SEB Livka & Livka 3 & L3 \\
\hline 22 & WC Šešula & Šešula 1 & $\mathrm{~S} 1$ & 46 & SEC Stračinska & Stračinska 1 & ST1 \\
\hline 23 & WC Šešula & Šešula 2 & S2 & 47 & SEC Stračinska & Stračinska 2 & ST2 \\
\hline 24 & WC Šešula & Šešula 3 & S3 & 48 & SEC Stračinska & Stračinska 3 & ST3 \\
\hline
\end{tabular}


Table 1 shows the location of each various anchor solutions/alternatives of location, and for each solution, the name and the tag is generated in relation to whether the first, second, or third variant solution are presented.

\subsection{Definition of GHS for Anchorage Location Priority Ranking}

Parallel with the alternative anchorage location definition, the goal tree was formed. The GHS designed for concept validation, along with the relationship between the objectives is shown in Figure 4 and their names, as well as the criteria names, can be found in Table 2 below.

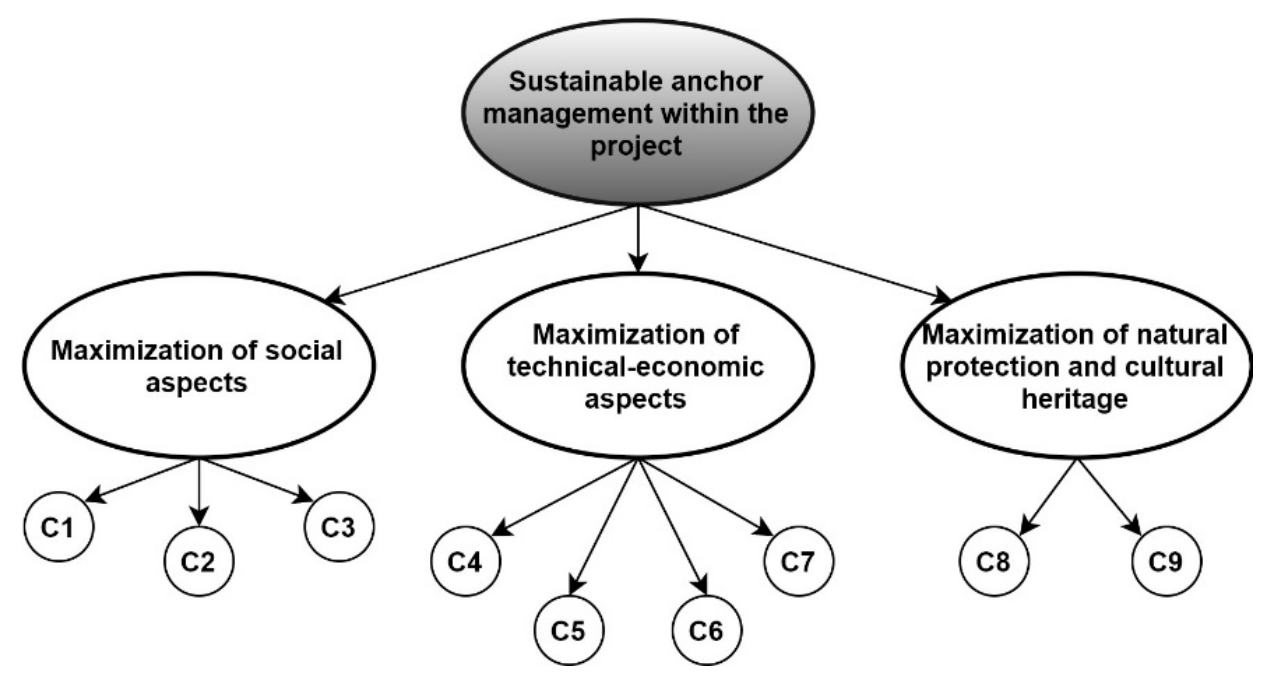

Figure 4. The goal hierarchy structure (GHS) for the problem of priority ranking of the anchorage locations.

Table 2. Label, title, and hierarchical level for each element of the goal tree.

\begin{tabular}{lll}
\hline \multicolumn{1}{c}{ Label } & \multicolumn{1}{c}{ Goal Title } & Level \\
\hline MG & Sustainable anchor management within the project & 1 \\
MO 1 & Maximization of social aspects & 2 \\
MO 2 & Maximization of technical-economic aspects & 2 \\
MO 3 & Maximization of natural protection and cultural heritage & 2 \\
C1 & Nearness to center attractions & 3 \\
C2 & Location by attractive nautical routes & 3 \\
C3 & Employment potential & 3 \\
C4 & Protection/exposure of the working water area & 3 \\
C5 & Working water area & 3 \\
C6 & Number of vessels in the working water area & 3 \\
C7 & Access roads (land)/issue of supply & 3 \\
C8 & Location by nature protection zones & 3 \\
C9 & Location according to cultural heritage protection zones & 3 \\
\hline
\end{tabular}

The group DM process started with a brainstorming session with all stakeholders included. The main goal was divided into three supporting objectives. These objectives referred to: first - the maximization of social aspects of the analyzed problem, second-the maximization of technical-economic aspects of the analyzed problem and third-the maximization of natural protection and cultural heritage within the analyzed area. These supporting objectives are the result of the stakeholders' consensus, and they are chosen in a manner to cover all aspects of the research problem. Each group of stakeholders, depending on their area of interest, suggested one of the three above-mentioned objectives. After the suggestions, all proposed objectives were subject to discussion, to ensure their alignment, and the final objectives that were included in the GHS were adopted by consensus of all stakeholders. These objectives were supports for a main goal achievement. 
The proposed methodology of the GHS design adapted by the stakeholders' agreement proved to be very practical in practice. It contributes to the objectivity of whole process.

Furthermore, the objectives are divided into several sub-objectives. These sub-objectives represent the last level of GHS, and they are determined as criteria at a time when stakeholders have reached a consensus about their relevance and measurability. Table 2 and Figure 4 show the goal tree with three objectives and nine sub-objectives/criteria. The criteria are marked with $\mathrm{C} i$, where $i$ is number of criteria, and it is determined by interval $i=1,2, \ldots, 9$. Social aspects are introduced through criteria from $\mathrm{C} 1$ to $\mathrm{C} 3$, technical-economic aspects through criteria from $\mathrm{C} 4$ to $\mathrm{C} 7$, and natural protection and cultural heritage through criteria C8 and C9.

Several criteria were excluded from the set of accepted criteria, and more precisely in three cases, a single criterion was defined from a group of criteria that were overlapping, and it was assigned to the objective group, to which it thematically conformed to the most (in a such manner, criteria C4, $\mathrm{C} 8$, and C9 were defined). It is important to emphasize that at the beginning, discussions were made for a much larger number of criteria that were subsequently excluded because they did not offer the possibility for comparing the anchorage locations. The number of criteria can be varied, depending on the particular area of research, as well as on the brainstorming between the stakeholders involvement in the DM process. One of the examples is an extremely important criterion of the bottom type, which was not taken into the overall set of criteria because the same type of bottom prevails in all valued areas. This is the reason for why the bottom type made no sense for use as a comparison criterion when prioritizing the ranking of anchorage locations.

Table 3 shows the list of the criteria, along with their label and a short description of the evaluation technique for each criterion, as well as the method of formatting the preference for each of the criteria separately (its preference function). The choice of the preference function is based on the author's experience in solving similar planner issues, and by consulting with the representatives of relevant stakeholders. The value of preference function is between $0-1$. The smaller the value of the function, the greater the indifference of the decision maker. If the value of function is closer to 1 , the preference is greater. If the decision maker has a strict preference, the preference function will be 1 . Which type of preference function will be used depends on the characteristics of the determined and used criteria [58]. For all the criteria, the V-shape preference function was chosen to express the relationship of the preference change between variant solutions. The V-shape is a linear function used for the moderate comparison of the themes, providing linear correlations between indifference (0) and strict preference (1). It should be emphasized that the Visual PROMETHEE software gives the possibility to determinate its own parameters to define the preference function if none of the proposed preferences correspond to the decision maker [59]. The last column in the table shows the problem type of each criterion. Five criteria refer to the problem of the minimum, which means that the best alternative locations are those of the lower values obtained by the evaluation techniques. Four criteria are related to the problem of the maximum, which means that the more valuable locations are those with higher values.

Table 3. Criteria description and technique for evaluation.

\begin{tabular}{|c|c|c|c|}
\hline Label & $\begin{array}{l}\text { Short Description of the Criteria and Technique for the Evaluation of } \\
\text { Investment Solutions }\end{array}$ & $\begin{array}{l}\text { Function } \\
\text { Preference }\end{array}$ & $\operatorname{Min} / \operatorname{Max}$ \\
\hline $\mathrm{C} 1$ & $\begin{array}{l}\text { Evaluation by this criterion is made by the measurement of the distance of } \\
\text { the anchorage from the centers of attraction (historical, cultural and } \\
\text { natural sights, entertainment centers, etc.) in NM. }\end{array}$ & V-shape & Min \\
\hline $\mathrm{C} 2$ & $\begin{array}{l}\text { Evaluation by this criterion is made by calculating the distance from the } \\
\text { attractive nautical routes measured in the NM from the anchorage, to the } \\
\text { nearest point of contact with the most attractive nautical route in the } \\
\text { vicinity of the island of Šlta. For the point of contact, the most } \\
\text { southeastern point of the island is selected, the Split gates passage. It is } \\
\text { chosen because it is the busiest nautical route in the vicinity of the island. }\end{array}$ & V-shape & Min \\
\hline
\end{tabular}


Table 3. Cont.

\begin{tabular}{|c|c|c|c|}
\hline Label & $\begin{array}{l}\text { Short Description of the Criteria and Technique for the Evaluation of } \\
\text { Investment Solutions }\end{array}$ & $\begin{array}{l}\text { Function } \\
\text { Preference }\end{array}$ & Min/Max \\
\hline $\mathrm{C} 3$ & $\begin{array}{l}\text { Evaluation by this criterion is provided by expert assessment, and it is } \\
\text { expressed as the potential number of employees on a single anchorage } \\
\text { location, which depends on the expected duration of the yacht stay during } \\
\text { one day, and the need to provide the nautical services to those yachts. } \\
\text { Thus, it is about of necessary number of work shifts that also depend on } \\
\text { the number of vessels to be served. }\end{array}$ & V-shape & Max \\
\hline $\mathrm{C} 4$ & $\begin{array}{l}\text { Evaluation by this criterion is based on a multiplicity of percentages of } \\
\text { water area which are endangered by the wind, with the risk weight. The } \\
\text { risk expressed by weights is determined by expert assessment as follows: } \\
1 \text {-anchorage with } 100 \% \text { protected water area; } 4 \text {-anchorage with water } \\
\text { area exposed to impact only in one sector; } 10 \text {-anchorage for short-term } \\
\text { residence only (entire water area is unprotected). }\end{array}$ & V-shape & Min \\
\hline C5 & $\begin{array}{l}\text { Evaluation by this criterion is provided as an area of one anchorage } \\
\text { location, which is expressed in } \mathrm{m}^{2} \text {. }\end{array}$ & V-shape & Max \\
\hline C6 & $\begin{array}{l}\text { Evaluation by this criterion is provided by the determination of the } \\
\text { maximum number of vessels that can be accommodated in the water area } \\
\text { of one anchorage location (assuming that the length of an average vessels } \\
\text { is } 15 \mathrm{~m} \text { ). }\end{array}$ & V-shape & Max \\
\hline $\mathrm{C} 7$ & $\begin{array}{l}\text { Evaluation is done by assessing alternative anchorage locations as follows: } \\
0 \text { - there is no access path; } 7 \text { - there is a macadam access road; } 10 \text { - there is } \\
\text { an asphalt access road. }\end{array}$ & V-shape & Max \\
\hline $\mathrm{C} 8$ & $\begin{array}{l}\text { Evaluation by this criterion is made by an expert assessment, with scores } \\
\text { from } 0 \text { to } 10 \text {, where assessment value is } 10 \text { if the anchorage is near a } \\
\text { protected natural area, and if there is a possibility of the maximum } \\
\text { permissible level of anchorage effect impinging on the protected area. On } \\
\text { the other hand, the assessment value is } 0 \text { if the anchorage does not have } \\
\text { an impact on the subject of protection. }\end{array}$ & V-shape & Min \\
\hline C9 & $\begin{array}{l}\text { Evaluation by this criterion is made by expert assessment, with scores } \\
\text { from } 0 \text { to } 10 \text {, where the assessment value is } 10 \text { if the anchorage is near } \\
\text { protected cultural heritage, and if there is a possibility of the maximum } \\
\text { permissible level of anchoring effect impinging on the protected area. The } \\
\text { opposite assessment value is } 0 \text { if the anchorage does not have an impact } \\
\text { on the subject of protection. }\end{array}$ & V-shape & Min \\
\hline
\end{tabular}

\subsection{Definition of Criteria Weights and the Decision Matrix}

Using the AHP method in the already established goal tree and the attitudes of stakeholders, criteria weights are provided. Multicriteria DM is supported by several strategies, also known as scenarios. Taking several preliminary scenarios (in this case three scenarios-one scenario for each group of stakeholders), the final so-called compromise scenario (fourth scenario) is defined, and it is used for the comparison/ranking of 48 anchorage locations. That fourth/final scenario is defined as a set of compromise criteria weights, each of which is the average of the preliminary weights of that same criterion over all preliminary scenarios. The arithmetic mean is used because of the stakeholders' preference. The weight of each criterion is expressed, as is shown in Table 4.

The most important criterion for the nautical and anchorage experts, as well as for local and regional government, is $\mathrm{C} 4$. Although, it is not defined as the most important for users, criterion $\mathrm{C} 4$ is also highly ranked according to its weight. This criterion is extremely important, because it defines the classification of the future anchorage (protected, unprotected or partially protected), and from that point of view, it is understandable why it is first ranked by the value of compromise weight. Criterion C3 is the most important for users, but the least important for experts. This criterion defines the employment potential, and depends on the classification of the anchorage, and on the number of vessels to be served. Criterion C6 is the least important criterion for administration and for users, and it refers to the maximum number of vessels that can be accommodated in the anchorage water area. Criterion C4 is the most important, and criterion C6 is the least important, as compromise scenarios. It was noted that experts gave a fairly low rating for the group of criteria belonging to the objective 
that is related to the maximization of natural protection and cultural heritage. This information can be explained by the fact that the proposed locations, prior to the selection of the locations for the model validation, were analyzed to determine their technical, natural, and historical properties, and according to that, all locations that violated the legal regulations in terms of impact on protected natural and cultural areas, and in terms of some other technical details, were automatically eliminated from a set of potential locations to be analyzed.

Table 4. Criteria weights for three scenarios, and compromise weights (fourth scenario).

\begin{tabular}{cccccc}
\hline \multirow{2}{*}{ Criteria Label } & \multicolumn{2}{c}{ Criteria Weights by Stakeholders Groups } & \multicolumn{2}{c}{ Compromise Weights } & $\%$ \\
\cline { 2 - 4 } & $\begin{array}{c}\text { Experts } \\
\text { (Scenario 1) }\end{array}$ & $\begin{array}{c}\text { Government } \\
\text { (Scenario 2) }\end{array}$ & $\begin{array}{c}\text { Users } \\
\text { (Scenario 3) }\end{array}$ & (Scenario 4) & \\
\hline C1 & 0.1703 & 0.0853 & 0.0543 & 0.1033 & $10.33 \%$ \\
C2 & 0.1703 & 0.0853 & 0.0543 & 0.1033 & $10.33 \%$ \\
C3 & 0.0266 & 0.1231 & 0.3106 & 0.1534 & $15.34 \%$ \\
C4 & 0.3998 & 0.1920 & 0.1360 & 0.2426 & $24.26 \%$ \\
C5 & 0.0315 & 0.0767 & 0.0547 & 0.0543 & $5.43 \%$ \\
C6 & 0.0314 & 0.0667 & 0.0467 & 0.0483 & $4.83 \%$ \\
C7 & 0.0535 & 0.1443 & 0.0668 & 0.0882 & $8.82 \%$ \\
C8 & 0.0583 & 0.1133 & 0.1383 & 0.1033 & $10.33 \%$ \\
C9 & 0.0583 & 0.1133 & 0.1383 & 0.1033 & $10.33 \%$ \\
Sum $(\Sigma)$ & 1.0000 & 1.0000 & 1.0000 & 1.0000 & $100.00 \%$ \\
\hline
\end{tabular}

When applying the AHP method, the consistency ratio (CR) is to be take into account. For three defined scenarios, the determined inconsistency was less than 0.1, which means that the weights were calculated properly $\left(\mathrm{CR}_{\text {scenario1 }}=0.06 ; \mathrm{CR}_{\text {scenario2 }}=0.09 ; \mathrm{CR}_{\text {scenario3 }}=0.07, \mathrm{CR}_{\text {scenario4 }}=0.08\right)$.

Afterwards, all the anchorage locations were evaluated by all criteria, and the decision matrix was formed, as is shown in Table 5 below. Each row gives the evaluation of one alternative through all criteria, and each column gives the evaluation of all alternatives through one criterion.

As is presented in Table 5, criteria C1-C9 are estimated or calculated values that describe each of the observed locations. The nearness-to-center attractions (C1) extend in values from 8.31 NM to $17.67 \mathrm{NM}$, with an average value of $11.67 \mathrm{NM}$. The minimum estimated values were obtained for locations N11 and N31, and the maximum for SU3. The second criterion (Location by attractive nautical routes) is provided in values $0.43-10.25 \mathrm{NM}$, and its average value is $5.02 \mathrm{NM}$. The location with the minimum estimated value is LM1, and the maximum is B3. The number of employments on each anchorage location are two for 25 observed locations, three for 21 locations and four for only two locations (N12 and N13). Protection/exposure of the working water area (C4) extends from 0.43 $\mathrm{NM}$ to $10 \mathrm{NM}$, which are also the smallest values (for locations N12 and L2) and the largest (location BK1), respectively. The largest working water area (C5) is location N13, with an area value of 82,500 $\mathrm{m}^{2}$, and the smallest value of $3563 \mathrm{~m}^{2}$ is location VL1. Also, the location N13 has the largest number of vessels (98), while Z1 has only two. Access roads are at nine locations, while 27 of them have macadam and 12 have asphalt access roads. The number of locations that do not have any estimated impact on nature protection zones is 30 . The number of locations that have major estimated impacts on nature is 0 , but there are six locations with a mild impact of value 2 , and three locations for each estimated impact value of $4,6,7$, and 8 , respectively. Also, the number of locations with no estimated impact on cultural heritage protection zones is 18, while those with a high value of 8 and 9 are in six and three locations, respectively.

The values in Table 5, together with the previously defined criteria characteristics (Tables 3 and 4) were introduced in the comparison procedure, according to the priority for inclusion in the spatial plan. The data given in the decision matrix and in Tables 3 and 4 were processed further using the PROMETHEE II method and complete ranking, according to each of scenario, was generated. The entire process was provided with the aid of the software Visual PROMETHEE [59]. It must 
be emphasized that the PROMETHEE II method provides a ranking by the mutual comparison of all anchorage locations by all criteria regarding the stakeholders' opinions, as expressed by criteria weights and by the selection of preference functions for each criterion.

Table 5. Decision matrix for the analyzed problem of anchorage location on the island of Šolta.

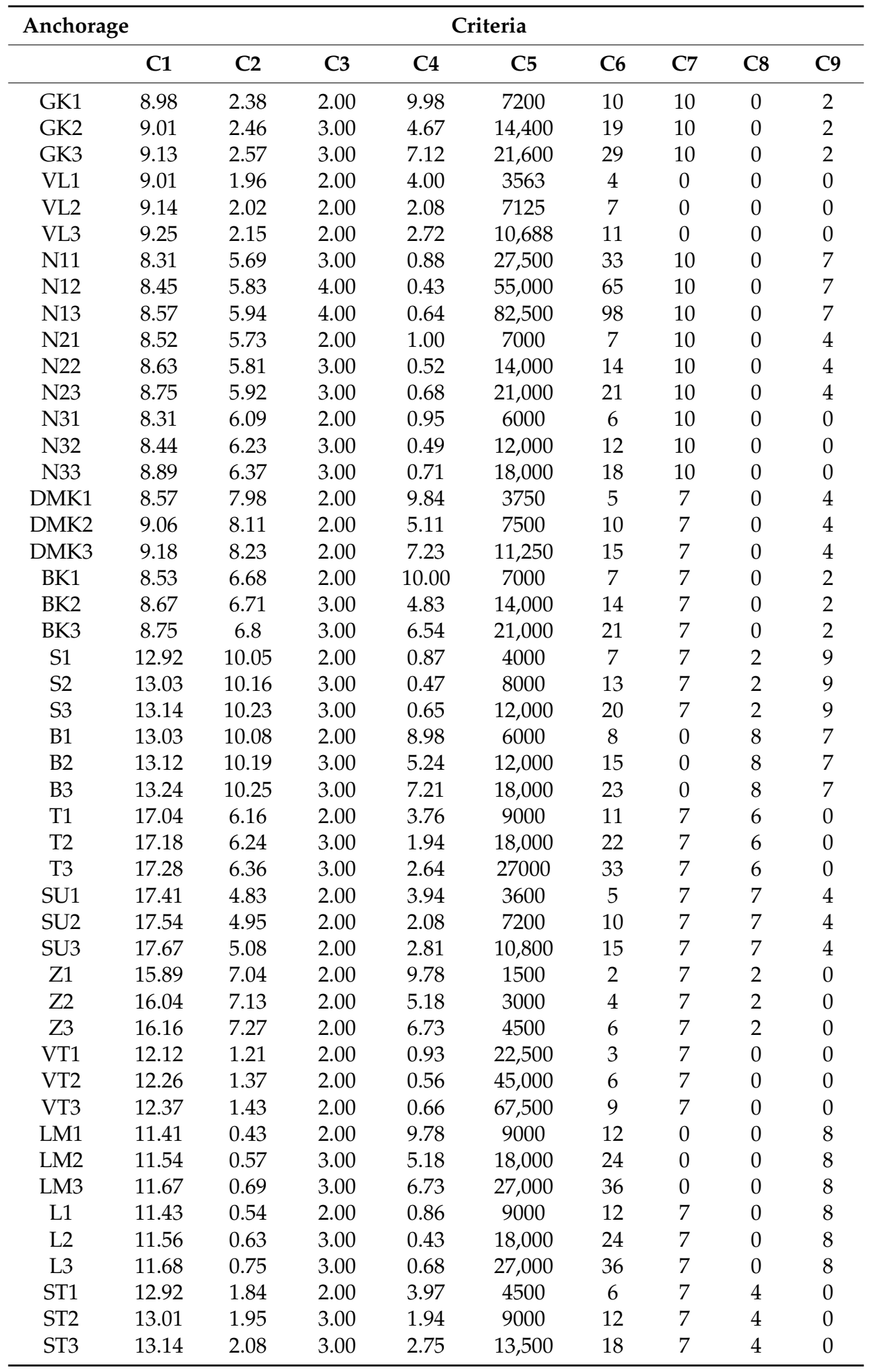




\section{Results and Discussion}

The proposed concept shows the complex DM process related to the spatial plan design for the development of the anchorage capacities. The DSC supports the design of this spatial plan, which defines the usage of the maritime space in a way that enables the maximization of the positive social and techno-economic impacts of the anchorage branch on the local community, while ensuring the highest possible protection of natural and cultural heritage. Additionally, while fulfilling the above requirements, it is able to process huge quantities of information and data that are relevant for DM priority, the multiplicity of criteria in different measurement units, their diversity in holistic approach, and conflict between goals, to include some of the anchorage sites within the future plan.

\subsection{Ranking of the Anchorage Locations}

Results of the analysis and their presentation in the form of the rank list with a Phi net flow are given in Table 6. The Phi net flow shows preferences among alternative locations, and it provides a complete ranking. A higher Phi net flow value for a certain location means that the location is better than others within the analyzed set. Consequently, a lower Phi net flow value shows an inferior preference for such a location. Also, the Phi net flow can provide a division/classification of anchorage locations according to their positive and negative Phi net values, showing how a certain group of locations is better or worse than another.

Table 6. Net flow results and complete ranking of 48 anchorage locations by compromise (fourth) scenario.

\begin{tabular}{|c|c|c|c|c|}
\hline Rank & Tag & Phi & Phi (+) & Phi (-) \\
\hline 1 & N13 & 0.3712 & 0.4353 & 0.0641 \\
\hline 2 & N12 & 0.3433 & 0.4106 & 0.0674 \\
\hline 3 & N11 & 0.2471 & 0.3219 & 0.0748 \\
\hline 4 & N33 & 0.2254 & 0.2661 & 0.0408 \\
\hline 5 & N23 & 0.1905 & 0.2471 & 0.0566 \\
\hline 6 & N22 & 0.1859 & 0.2445 & 0.0586 \\
\hline 7 & VT3 & 0.1772 & 0.2537 & 0.0765 \\
\hline 8 & VT2 & 0.1595 & 0.2373 & 0.0779 \\
\hline 9 & L3 & 0.1552 & 0.2455 & 0.0903 \\
\hline 10 & N32 & 0.1529 & 0.2273 & 0.0744 \\
\hline 11 & L2 & 0.1476 & 0.2389 & 0.0913 \\
\hline 12 & GK2 & 0.1375 & 0.2201 & 0.0826 \\
\hline 13 & N31 & 0.1344 & 0.2164 & 0.082 \\
\hline 14 & VT1 & 0.1302 & 0.213 & 0.0828 \\
\hline 15 & ST2 & 0.1024 & 0.2059 & 0.1035 \\
\hline 16 & N21 & 0.0893 & 0.1891 & 0.0998 \\
\hline 17 & ST3 & 0.0869 & 0.1977 & 0.1108 \\
\hline 18 & GK3 & 0.0851 & 0.2126 & 0.1275 \\
\hline 19 & T3 & 0.0687 & 0.2491 & 0.1804 \\
\hline 20 & BK2 & 0.0606 & 0.1731 & 0.1125 \\
\hline 21 & VL2 & 0.0511 & 0.1855 & 0.1344 \\
\hline 22 & L1 & 0.0472 & 0.1784 & 0.1311 \\
\hline 23 & VL3 & 0.0379 & 0.1771 & 0.1392 \\
\hline 24 & BK3 & 0.0258 & 0.1681 & 0.1424 \\
\hline 25 & VL1 & -0.0018 & 0.1621 & 0.1639 \\
\hline 26 & $\mathrm{~T} 2$ & -0.0019 & 0.1744 & 0.1763 \\
\hline 27 & S3 & -0.0254 & 0.1632 & 0.1886 \\
\hline 28 & $\mathrm{~S} 2$ & -0.0273 & 0.1629 & 0.1902 \\
\hline 29 & ST1 & -0.0312 & 0.1365 & 0.1677 \\
\hline 30 & LM2 & -0.0376 & 0.1638 & 0.2014 \\
\hline 31 & LM3 & -0.0637 & 0.1661 & 0.2298 \\
\hline 32 & DMK2 & -0.0733 & 0.106 & 0.1793 \\
\hline
\end{tabular}


Table 6. Cont.

\begin{tabular}{ccccc}
\hline Rank & Tag & Phi & Phi (+) & Phi (-) \\
\hline 33 & GK1 & -0.0867 & 0.1468 & 0.2335 \\
34 & S1 & -0.1181 & 0.1101 & 0.2281 \\
35 & DMK3 & -0.1239 & 0.0953 & 0.2192 \\
36 & Z2 & -0.1309 & 0.0932 & 0.2242 \\
37 & T1 & -0.1375 & 0.0994 & 0.2369 \\
38 & SU2 & -0.149 & 0.0983 & 0.2474 \\
39 & BK1 & -0.1576 & 0.1037 & 0.2614 \\
40 & SU3 & -0.164 & 0.0905 & 0.2545 \\
41 & Z3 & -0.1712 & 0.083 & 0.2542 \\
42 & DMK1 & -0.1957 & 0.0881 & 0.2837 \\
43 & SU1 & -0.2011 & 0.0743 & 0.2754 \\
44 & LM1 & -0.2453 & 0.093 & 0.3383 \\
45 & Z1 & -0.2501 & 0.0735 & 0.3236 \\
46 & B2 & -0.2658 & 0.0787 & 0.3445 \\
47 & B3 & -0.3078 & 0.074 & 0.3818 \\
48 & B1 & -0.4458 & 0.0147 & 0.4606 \\
\hline
\end{tabular}

Table 6 gives the results of the rank list of 48 anchorage locations with the obtained Phi net values. Positive and negative Phi net values are calculated by the PROMETHEE I method, which gives a partial ranking of alternatives. The largest Phi $(+)$ of 0.4353 has location N13, while the largest Phi $(-)$ of 0.4606 has B1. Also, location B1 has the smallest value of Phi $(+)$ of 0.0147 , and the smallest Phi(-) has N33 with a value of 0.0408 . The location B1 has achieved last position with both (positive and negative) Phi values, according to partial ranking, and also according to the overall ranking obtained by the PROMETHEE II method.

It can be seen in Table 6 that the location of the anchorage in the Nečujam area (N13) is the best ranked, and with a net value of $\Phi=0.3712$. The lowest ranked location is Balkun 1 (B1) and it has value of the net flow of $\Phi=-0.4458$. It is also interesting that 24 locations have a positive net Phi flow, which means that they are better than the rest of locations, while 24 locations have a negative Phi flow, which indicates their weaker status, compared to the first 24 . Figure 5 gives a graphic presentation of the net flow results, and the PROMETHEE II complete priority ranking for scenario four. The locations best ranked and separated from the others are N13 and N12. After them, a group of 46 alternative locations are followed.

Although the deviations between the grouped alternatives are very small, the difference between the first and the last alternative is significant, with a net flow of $\Phi=0.5549$. The worst ranked alternative location, $\mathrm{B} 1$, is dislocated from the other alternative locations, and it indicates the largest difference between two following ranked location (B3 and B1), which are expressed with a net flow of $\Phi=-0.1380$.

In Table 7, the weight stability intervals (WSI) are shown. In the process of applying a stability analysis, the weight of each criterion is usually compared to the weights of other criteria in such a manner that its weight value is changing, while the weight values of all other criteria are constant. Within the interval [wmin \%, wmax \%] the weight value of the considered criterion can be changed without changing the final rank of the anchorage locations obtained, by applying PROMETHEE II, with the weights of the other criteria remaining constant. Although the determination of weight, in this case, is the subjective assessment of each group of stakeholders, it is important to be very careful when defining them. WSI results (Scenario 1, Scenario 2, Scenario 3) indicate that the final rank list is stable to minor changes of criteria weights. This means that the stability of the final ranking is quite sensitive, and that the use of some different weights whose values vary for small amounts will result in a change of anchorage location priority ranking. A slightly higher stability interval is determined for Scenario 4, but this was expected, because compromise weights are defined as the arithmetic mean of the criteria weights of multiple scenarios. 


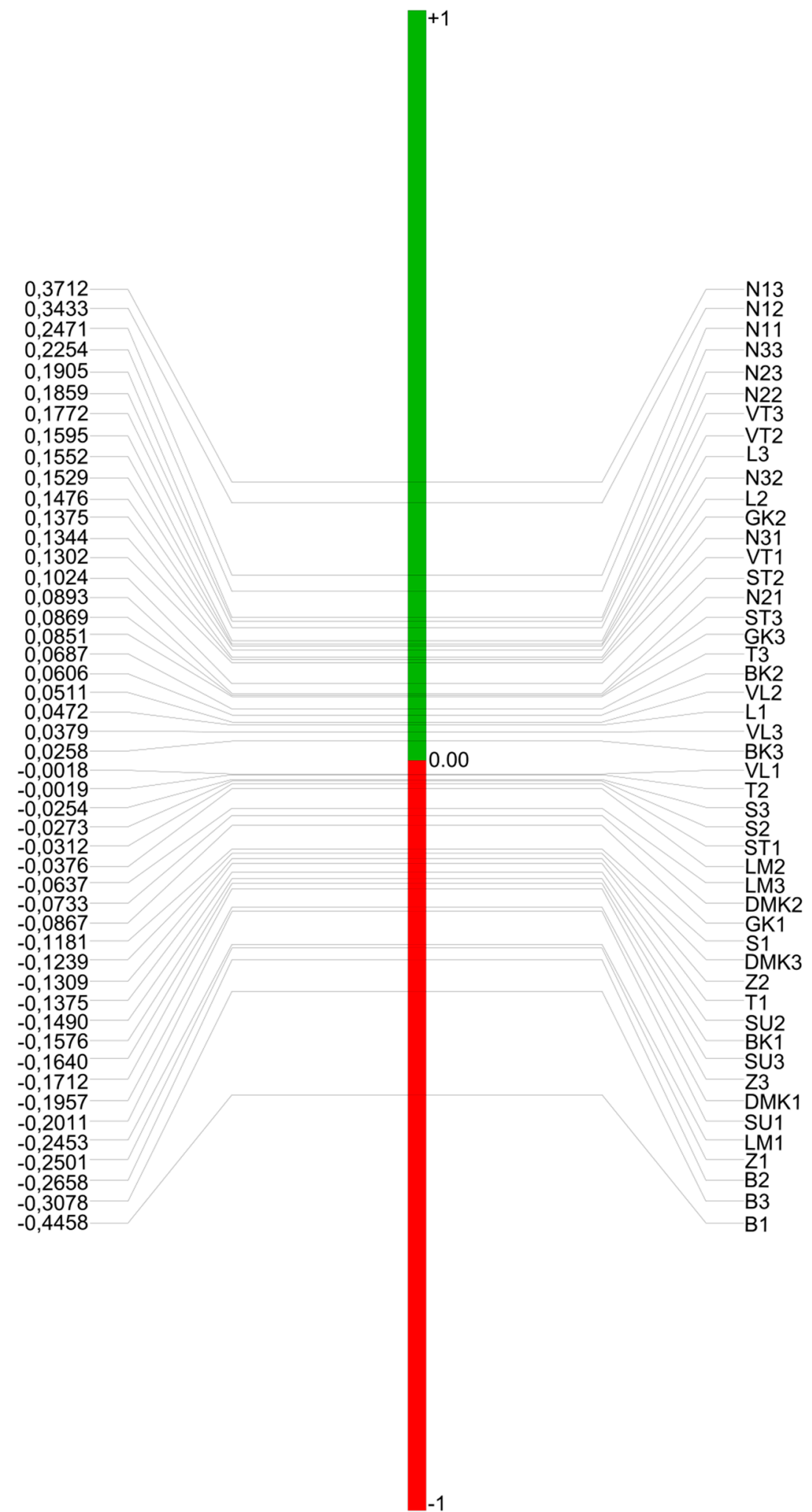

Figure 5. Graphic presentation of net flow results and PROMETHEE II complete priority ranking for a compromise scenario. 
Table 7. Weight stability intervals.

\begin{tabular}{|c|c|c|c|c|c|c|c|c|c|}
\hline \multirow[t]{2}{*}{ Label } & \multirow[t]{2}{*}{ Name } & \multicolumn{2}{|c|}{ Scenario 1 (Experts) } & \multicolumn{2}{|c|}{$\begin{array}{c}\text { Scenario 2 } \\
\text { (Government) }\end{array}$} & \multicolumn{2}{|c|}{ Scenario 3 (Users) } & \multicolumn{2}{|c|}{$\begin{array}{c}\text { Scenario } 4 \\
\text { (Compromise) }\end{array}$} \\
\hline & & $w_{\min }(\%)$ & $\mathrm{w}_{\max }(\%)$ & $w_{\min }(\%)$ & $w_{\max }(\%)$ & $\mathrm{w}_{\min }(\%)$ & $w_{\max }(\%)$ & $w_{\min }(\%)$ & $w_{\max }(\%)$ \\
\hline $\mathrm{C} 1$ & $\begin{array}{l}\text { Location by attractive } \\
\text { nautical routes }\end{array}$ & 17.03 & 17.29 & 8.53 & 8.61 & 5.42 & 5.61 & 9.62 & 10.40 \\
\hline $\mathrm{C} 2$ & $\begin{array}{c}\text { Employment } \\
\text { potential }\end{array}$ & 16.84 & 17.03 & 8.52 & 8.58 & 5.43 & 5.65 & 10.15 & 10.54 \\
\hline $\mathrm{C} 3$ & $\begin{array}{l}\text { Protection/exposure } \\
\text { of working water area }\end{array}$ & 2.66 & 3.34 & 12.31 & 12.70 & 30.62 & 31.06 & 14.95 & 16.54 \\
\hline $\mathrm{C} 4$ & $\begin{array}{c}\text { Water area working } \\
\text { area }\end{array}$ & 39.71 & 39.98 & 19.19 & 19.20 & 13.46 & 13.61 & 24.18 & 25.00 \\
\hline C5 & $\begin{array}{c}\text { Number of vessels in } \\
\text { the working water } \\
\text { area }\end{array}$ & 3.15 & 3.30 & 7.30 & 7.68 & 5.24 & 5.66 & 4.47 & 6.08 \\
\hline C6 & $\begin{array}{l}\text { Access roads } \\
\text { (land)/issue of } \\
\text { supply }\end{array}$ & 3.14 & 4.11 & 6.67 & 6.71 & 4.50 & 4.71 & 3.99 & 5.83 \\
\hline $\mathrm{C} 7$ & $\begin{array}{l}\text { Location by nature } \\
\text { protection zones }\end{array}$ & 5.08 & 5.63 & 14.34 & 14.70 & 6.55 & 6.68 & 8.52 & 9.12 \\
\hline $\mathrm{C} 8$ & $\begin{array}{l}\text { Location according to } \\
\text { cultural heritage } \\
\text { protection zones }\end{array}$ & 5.83 & 6.00 & 11.33 & 11.42 & 13.82 & 13.88 & 9.92 & 10.40 \\
\hline C9 & $\begin{array}{c}\text { Location by attractive } \\
\text { nautical routes }\end{array}$ & 5.45 & 5.83 & 11.13 & 11.33 & 13.83 & 13.86 & 9.96 & 10.56 \\
\hline
\end{tabular}

The next step is the introduction of constraints that need to be defined by relevant stakeholders. In this case, constraints are defined by nautical and anchorage experts, and local and regional government. The constraints are introduced by the PROMETHEE V method, and according to such an approach, they are defined by a set of $0-1$ integer linear inequalities that are combined with a goal function gained by the PROMETHEE II method, as described above. All 16 constraints provide the introduction of spatial-functional considerations. All constraints are formed in a way to accomplish the following requirements: a uniform anchorage development on the whole island (foreseeing the possibility of anchoring in each bay or cove), and no more than one anchorage in each cove/bay (which in this case means one of three variant solutions) until all bays or coves have one anchorage constructed. According to this, only one variant solution at each location can be included in the maritime spatial plan. Exactly 16 inequalities by which the above described constraints are introduced are shown below in the second column of Table 8 .

Table 8. Spatial-functional constrains introduced as a set of $16(0-1)$ integer linear inequalities.

\begin{tabular}{ccc}
\hline No. & Location (the Name of Bay or Cove) & Constraint \\
\hline 1 & NEC Gornja Krušica & $x_{1}+x_{2}+x_{3}=1$ \\
2 & NEC Vela luka & $x_{4}+x_{5}+x_{6}=1$ \\
3 & NB Nečujam 1 & $x_{7}+x_{8}+x_{9}=1$ \\
4 & NB Nečujam 2 & $x_{10}+x_{11}+x_{12}=1$ \\
5 & NB Nečujam 3 & $x_{13}+x_{14}+x_{15}=1$ \\
6 & NC Donja Krušica i Mala Krušica & $x_{16}+x_{17}+x_{18}=1$ \\
7 & NB Rogač & $x_{19}+x_{20}+x_{21}=1$ \\
8 & WC Šešula & $x_{22}+x_{23}+x_{24}=1$ \\
9 & WC Balkun & $x_{25}+x_{26}+x_{27}=1$ \\
10 & SC Tatinja & $x_{28}+x_{29}+x_{30}=1$ \\
11 & SC Senjska uvala & $x_{31}+x_{32}+x_{33}=1$ \\
12 & SC Zaglav & $x_{34}+x_{35}+x_{36}=1$ \\
13 & SEC Vela travna & $x_{37}+x_{38}+x_{39}=1$ \\
14 & SEB Livka-Motika & $x_{40}+x_{41}+x_{42}=1$ \\
15 & SEB Livka & $x_{43}+x_{44}+x_{45}=1$ \\
16 & SEC Stračinska & $x_{46}+x_{47}+x_{48}=1$ \\
\hline
\end{tabular}


The first column of Table 8 shows the number of the inequality; the second column gives the name of the location on the island, meaning the name of the bay or cove. The third column provides the constraint for each bay or cove that is derived by using the following formula:

$$
x_{n-1}+x_{n}+x_{n+1}=1
$$

where $\mathrm{n}=2 * a+(a-1)$ and $\mathrm{a}=1,2,3, \ldots, 16$.

The results of the PROMETHEE V method are shown in Table 9. These 16 anchorage locations should be included in a spatial plan as one of its several categories for small vessels, as a suitable framework for the sustainable development of that nautical tourism branch.

Table 9. Location set for the anchorage construction.

\begin{tabular}{cccc}
\hline No. & Location & Anchor & Tag \\
\hline 1 & NB Nečujam & Nečujam 13 & N13 \\
2 & NB Nečujam & Nečujam 33 & N33 \\
3 & NB Nečujam & Nečujam 23 & N23 \\
4 & SEC Vela travna & Vela travna 3 & VT3 \\
5 & SEB Livka & Livka 3 & L3 \\
6 & NEC Gornja Krušica & Gornja Krušica 2 & GK2 \\
7 & SEC Stračinska & Stračinska 2 & ST2 \\
8 & SC Tatinja & Tatinja 3 & T3 \\
9 & North-cove Rogač & Bocanac and Kašjun 2 & BK2 \\
10 & NEC Vela luka & Vela luka 2 & VL2 \\
11 & WC Šešula & Šešula 3 & S3 \\
12 & SEC Livka & Livka-Motika 2 & LM2 \\
13 & NC Donja Krušica, Mala Krušica & Donja Krušica, Mala Krušica 2 & DMK2 \\
14 & SC Zaglav & Zaglav 2 & Z2 \\
15 & SC Senjska uvala & Senjska uvala 2 & SU2 \\
16 & WC Balkun & Balkun 2 & B2 \\
\hline
\end{tabular}

Table 9 shows that nine alternatives belong to the second type of variant solution, (alternatives marked with number two), while the seven alternatives belong to the third type of variant solutions (alternatives marked with number three). Not even a single alternative location designed as the first type of variant solution was selected to be entered within the spatial plan. That has been justified in the case of Šolta, considering the assumption of expert stakeholders about the unsuitability of the first type of variant solution for inclusion in the spatial plan (stated when the approach for the determination of alternative locations was established). On the other hand, the set presented within Table 4 stands as a compromised solution according to the opinions of all stakeholders and in line with legal acts. Having that in mind, it can be concluded that the dominant weights of the $\mathrm{C} 3$ and $\mathrm{C} 4$ criteria in the compromise scenario must be reduced, or the area of the first type must be increased if users want to include the first type of variant solutions in the spatial plan (stated in the same time). Since safety importance (C4) cannot be reduced, it is suggested to the government to design and provide alternative solutions to increase employment. That is because the users are not willing to increase the area of the first type of variant solution. This fact shows how important and tricky the process of alternatives generation can be.

\subsection{Discussion}

The most common limitations of DSC are the gathering of all stakeholders at the same time, and achieving a consensus in terms of defining the criteria weight. As stated in the paper, common meetings are usually attended by representatives of certain stakeholders that are involved in the DM process, as well as representatives of the stakeholders' groups, assuming that they are responsible for representing the standpoint of a group in the name that they are acting for. Fewer difficulties have arisen in explaining the principles of the method to the stakeholders, and here, it is very important to 
pay particular attention to creating stakeholders' confidence in the methods used. It is also important to note that the criteria can be added or subtracted, depending on the particular problem, and additional groups of stakeholders or their subgroups can be formed. The concept is defined by theory, as an open system that is adaptive (by adding, removing, or replacing criteria, stakeholders, and constraints). Defined GHS by stakeholders consists of nine criteria that are used for assessing 48 anchorage locations. With the aid of the PROMETHEE II method, the locations are ranked with their net values, and according to the rank, the Nečujam area (N13) is ranked first, while the last position was Balkun 1 (B1). Spatial-functional constraints are also modified by stakeholders by using the PROMETHEE V method. Constraints are described by 16 inequalities. These inequalities represent 16 anchorage locations that should be included in the spatial plan. Apart from spatial functionalities, financial constraints can be also added. Figure 6 represents the spatial distribution of anchorages, according to the type of variant. Red dots are the second type of variant solutions, and blue ones present the third type of variant solution.

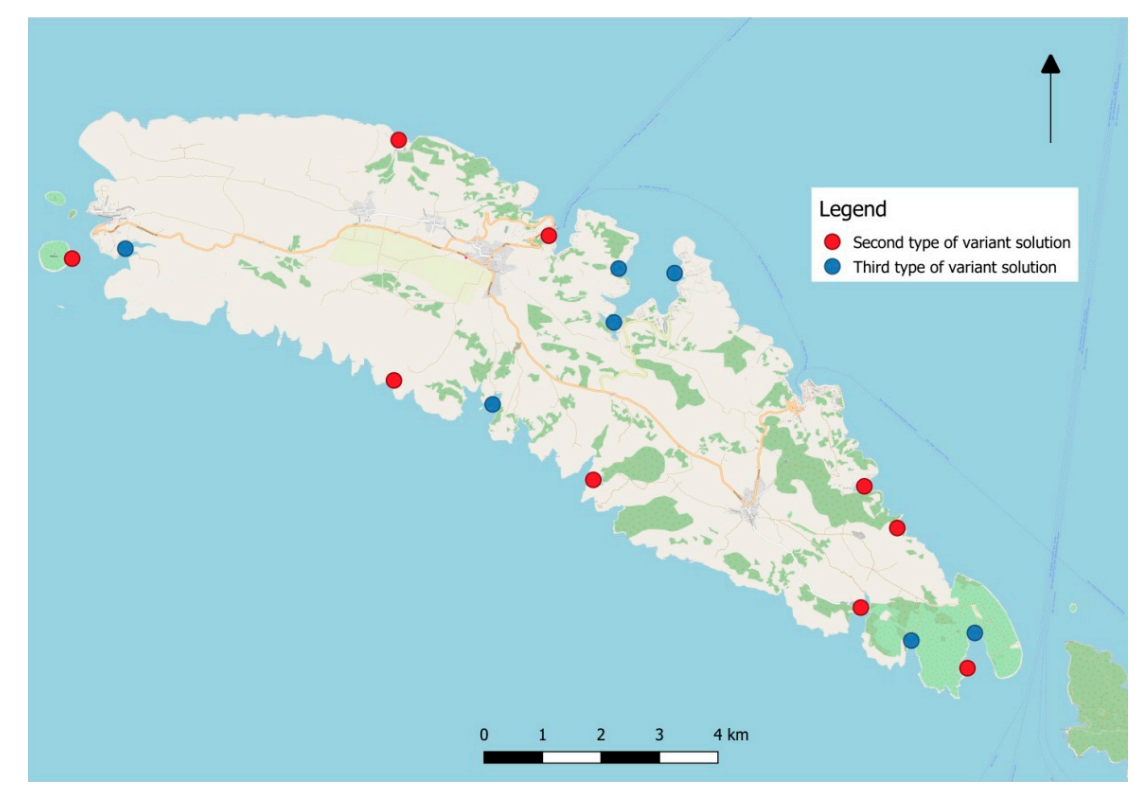

Figure 6. Spatial distribution of anchorages according to the type of variant.

Previous studies made on this issue have not used this approach, which improves the DM process for sustainable maritime spatial planning, which has so far been unsystematic and subjectively oriented. The new DSC has proven to be the most appropriate approach to resolving composite and extensive task such as this one. The DSC has not yet been used for these types of planning activities, but it has been used in the protection of environment, ecology, biodiversity, coastal, and seabed habitat features, the planning of marine traffic, and the site identification (selection) of various industrial facilities. As mentioned in the Introduction, no concept for DM was developed for the planning of anchorage construction as an integral approach to sustainable DM within maritime spatial planning.

According to the above-mentioned, research on scientific and professional literature has been expanded upon, in the use of DS in maritime spatial planning, and it has been noted that most of the research was related to DS usage in the berth allocation problem [27-36]. None of these authors conducted studies in which all affected groups (government, experts, and users) were involved in the strategy selection, and none of them gave a solution for the spatial plan design for the development of anchorage capacities with the approach of DSC as a proven high quality "tool" for decision-makers dealing with this issue. Oz et al. [37] in their study, introduced novel performance metrics aimed at measuring safety in anchorage planning, and proposed a multiobjective optimization strategy in order to maximize the utilization of the anchorage area and to minimize the risk of accidents at the same time, using a strategy called MOAP (Multi-Objective Anchorage Planner). The differences 
from this study are that it did not use DSC in combination with multicriteria DM and multicriteria methods that will provide support to the spatial planning specialists in designing spatial plans that are related to anchorage capacities development, using aspects of sociological, technical-economic, and the protection of natural and cultural heritage.

\section{Conclusions}

The research hypothesis, by which it is possible to establish a systematic approach to maritime spatial planning, based on DSS logic and multicriteria analysis, which as a result, gives a model for the planning of anchorage locations, has been confirmed. The proposed model is given in the form of DSC, and is validated on a real example. Validation was carried out on the island of Šolta in Croatia, and it showed a number of concrete insights and contributions for planning for the island of Šolta itself. The proposal is easily applicable for the area of Croatia, with relatively minor changes for any other area in the world. It has been shown that the proposed approach is adaptable, as it enables the inclusion of a variety of stakeholders and their different manners through the whole body of the planning process, while respecting professional, scientific, and research knowledge. Thus, a significant contribution has been made in forming the way in which stakeholders are involved. It should also be noted that the establishment of the hierarchical structure of objectives and the determination of the criteria weights, with the participation of all stakeholders and with the application of the AHP method in a suitable way, ensured the consistency of DM during the planning process, uniform observation of stakeholder's manners, transparency of the process, and perhaps most importantly, meeting of relevant stakeholders with all relevant aspects of the design and content of the future plan. The application of multi-criteria methods from the PROMETHEE family (II and V) proved to be a very good choice, because it was well accepted by stakeholders, and it provided a simple insight into priority ranking procedures, as well as into introducing constraints whilst retaining stakeholder's manners and their influence on the DM process under legislative authorities with the utmost respect for them. The process of generating alternatives has also proven to be well-formed. In the validation process, stakeholders decided to analyze all possible locations, and the principle of generating variant solutions at each location was described over their area, because over it, numerous influences relevant to stakeholders can be expressed, from nature protection to the number of employees, which can then be relatively easily assessed by the proposed criteria. Altogether, this approach has proven to be adequate for the intended purpose, and it could be, given the fact that it is an open type of system, the starting point for further research on the integrated coastal water management approach for the planning and design of anchorage location plans. The research conveys a good deal of relevant factual information, and it gives comprehensive research references on the mentioned issue. The methods used are straightforward, and the results are very useful for sustainable DM, in the planning of anchorage locations as one of the MSP components. The concrete result is a suggestion of locations that should jointly complement a MSP with anchorage locations on the island of Šolta. The resilience of coastal ecosystems related to anchoring will be improved upon, with the proper distribution of anchorage locations through the coast, which enable steady tourist development of the island of Šolta, and in this way, the problem of anchorage concentration on a relatively small area is avoided. Also, in this way, the biodiversity of the area is protected by the selection of the anchorage locations that will have minimum impacts on the ecosystem.

The new DSC is unique and easy to apply, because it improves the DM process, and it gives free expression of an attitude that moves the boundaries of the previous DM by governments, project managers, spatial planners, users etc., on this issue. The authorities involved in the governance of an area have recognized the concept as being relevant for input into future definitions of regulations that are normative in the planning of the anchorage locations as components of MSP. The same approach can be applied to other components of MSP, and their integration is a challenge for future research.

Author Contributions: Conceptualization, N.J., J.K. and K.R.; Data curation, N.J., J.K. and K.R.; Formal analysis, N.J., J.K. and K.R.; Investigation, N.J., J.K, and K.R.; Methodology, N.J., J.K. and K.R.; Software, N.J., J.K. and K.R.; 
Supervision, N.J., J.K. and K.R.; Validation, N.J., J.K. and K.R.; Visualization, N.J., J.K., and K.R.; Writing—original draft, N.J., J.K., and K.R.; Writing-review \& editing, N.J., J.K. and K.R.

Funding: This research is partially supported through project KK.01.1.1.02.0027, a project co-financed by the Croatian Government and the European Union through the European Regional Development Fund-the Competitiveness and Cohesion Operational Programme.

Conflicts of Interest: The authors declare no conflict of interest.

\section{References}

1. European Parliament and Council (EPC). Directive 2014/89/EU of the European parliament and of the council of 23 July 2014 establishing a framework for maritime spatial planning. Off. J. Eur. Union 2014, 257, 135-145.

2. European Commission (EC). Commission Welcomes Parliament's Adoption of Maritime Spatial Planning Legislation. IP-14-459_EN. 2014. Available online: http:/ / europa.eu/rapid/press-release_IP-14-459_en.htm (accessed on 13 September 2017).

3. Kovacic, M.; Zekic, A.; Rukavina, B. Maritime spatial planning in Croatia-necessity or opportunity for balanced development. Sci. J. Marit. Res. 2016, 30, 82-87.

4. UNESCO-IOC. Available online: http://msp.ioc-unesco.org/world-applications/europe/croatia/ (accessed on 25 September 2017).

5. Depellegrin, D.; Menegon, S.; Farella, G.; Ghezzo, M.; Gissi, E.; Sarretta, A.; Venier, C.; Barbanti, A. Multi-objective spatial tools to inform maritime spatial planning in the Adriatic Sea. Sci. Total Environ. 2017, 609, 1627-1639. [CrossRef] [PubMed]

6. Gee, K.; Kannen, A.; Adlam, R.; Brooks, C.; Chapman, M.; Cormier, R.; Fischer, C.; Fletcher, S.; Gubbins, M.; Shucksmith, R.; et al. Identifying culturally significant areas for marine spatial planning. Ocean Coast. Manag. 2017, 136, 139-147. [CrossRef]

7. Ehler, C.N.; Douvere, F. Marine Spatial Planning: A Step-by-Step Approach Toward Ecosystem-based Management. IOC Manual and Guides No. 53 (Intergovernmental Oceanographic Commission and Man and the Biosphere Programme). 2009. Available online: http://unesdoc.unesco.org/images/0018/001865/ 186559e.pdf (accessed on 16 September 2018).

8. Schaefer, N.; Barale, V. Maritime spatial planning: Opportunities \& challenges in the framework of the EU integrated maritime policy. J. Coast. Conserv. 2011, 15, 237-245.

9. Tools4MSP. Available online: http:/ / data.adriplan.eu/tools4msp/ (accessed on 27 July 2018).

10. Cvitanovic, C.; Fulton, C.J.; Wilson, S.K.; van Kerkhoff, L.; Cripps, I.L.; Muthiga, N. Utility of primary scientific literature to environmental managers: An international case study on coral-dominated marine protected areas. Ocean Coast. Manag. 2014, 102, 72-78. [CrossRef]

11. de Jonge, V.N.; Pinto, R.; Turner, R.K. Integrating ecological, economic and social aspects to generate useful management information under the EU Directives' 'ecosystem approach'. Ocean Coast. Manag. 2012, 68, 169-188. [CrossRef]

12. Turban, E. Decision Support and Expert System: Management Support System; Macmillan Publishing Company: New York, NY, USA, 1993.

13. Regulation of Classification and Categorization of Nautical Tourism Ports (NN, 72/08). Available online: https:/ / narodne-novine.nn.hr/clanci/sluzbeni/2008_06_72_2402.html (accessed on 13 March 2017).

14. Ministry of the Sea, Transport and Infrastructure, Republic of Croatia (MSTI). Strategy for Nautical Tourism Development in Period 2009. 2008. Available online: http:/ / www.mppi.hr/UserDocsImages/Strategija\% 20razvoja\%20nautickog\%20turizma\%20HR\%201.pdf (accessed on 13 October 2017).

15. Favro, S.; Kovačić, M.; Domijan, N.; Punda, S.; Bročić, P.; Horvat, B.; Pušić, D.; Hydrographic Institute of Croatia (HIRC). Action Plan for the Development of Nautical Tourism in Split-Dalmatia County. 2013. Available online: http:/ / adriatic-expert.hr/projects / (accessed on 22 March 2017).

16. Ministry of tourism, Republic of Croatia. Proposal for Tourism Development Strategy of the Republic of Croatia Until 2020. 2013. Available online: http:/ /www.mint.hr/UserDocsImages/Tourism_development_ strategy_2020.pdf (accessed on 13 October 2017). 
17. Horak, S.; Marušić, Z.; Carić, H.; Sever, I. Action Plan for the Development of Nautical Tourism, Institute for Tourism. 2015. Available online: https://mint.gov.hr/UserDocsImages//AA_2018_c-dokumenti/akcijski\% 20planovi / /005_151022_akc_p_nautic.pdf (accessed on 22 March 2017).

18. Pınarbaşı, K.; Galparsoroa, I.; Borjaa, A.; Stelzenmüllerb, V.; Ehlerc, C.N.; Gimpelb, A. Decision support tools in marine spatial planning: Present applications, gaps and future perspectives. Mar. Policy 2017, 83, 83-91. [CrossRef]

19. Cartwright, J.; Caldwell, C.; Nebiker, S.; Knight, R. Putting Flow-Ecology Relationships into Practice: A Decision-Support System to Assess Fish Community Response to Water-Management Scenarios. Water 2017, 9, 196. [CrossRef]

20. Sutrisno, D.; Gill, S.N.; Suseno, S. The development of spatial decision support system tool for marine spatial planning. Int. J. Digit. Earth 2017, 1-17. [CrossRef]

21. Wu, K.K.; Zhang, L.P. Application of environmental risk assessment for strategic decision-making in coastal areas: Case studies in China. J. Environ. Plan. Manag. 2016, 59, 826-842. [CrossRef]

22. Lonsdale, J.A.; Weston, K.; Barnard, S.; Boyes, S.J.; Elliott, M. Integrating management tools and concepts to develop an estuarine planning support system: A case study of the Humber Estuary, Eastern England. Mar. Pollut. Bull. 2015, 100, 393-405. [CrossRef] [PubMed]

23. Davies, A.J.; Hope, M.J. Bayesian inference-based environmental decision support systems for oil spill response strategy selection. Mar. Pollut. Bull. 2015, 96, 87-102. [CrossRef] [PubMed]

24. Mercantini, J.M. Building a Domain Ontology to Design a Decision Support Software to Plan Fight Actions Against Marine Pollutions. Risk Cogn. 2015, 80, 197-227. [CrossRef]

25. Huang, W.; Corbett, J.J.; Jin, D. Regional economic and environmental analysis as a decision support for marine spatial planning in Xiamen. Mar. Policy 2015, 51, 555-562. [CrossRef]

26. Valentini, E.; Filipponi, F.; Nguyen Xuan, A.; Passarelli, F.M.; Taramelli, A. Earth Observation for Maritime Spatial Planning: Measuring, Observing and Modeling Marine Environment to Assess Potential Aquaculture Sites. Sustainability 2016, 8, 519. [CrossRef]

27. John, A.; Yang, Z.; Riahi, R.; Wang, J. A Decision Support System for the Assessment of Seaports' Security Under Fuzzy Environment. Maritime Transportation. Intell. Syst. Ref. Lib. 2017, 131, 145-177. [CrossRef]

28. Pietrzykowski, Z.; Wołejsza, P.; Borkowski, P. Decision Support in Collision Situations at Sea. J. Navig. 2017, 70, 447-464. [CrossRef]

29. Lazarowska, A. A new deterministic approach in a decision support system for ship's trajectory planning. Expert Syst. Appl. 2017, 71, 469-478. [CrossRef]

30. Sinesi, S.; Altieri, M.G.; Marinelli, M.; Dell'Orco, M. A multivariate logic decision support system for optimization of the maritime routes. In Proceedings of the 5th IEEE International Conference on Models and Technologies for Intelligent Transportation Systems (MT-ITS), Naples, Italy, 26-28 June 2017.

31. Kapetanis, G.N.; Psaraftis, H.N.; Spyrou, D. A simple synchro-modal decision support tool for the Piraeus container terminal. Transp. Res. Arena 2016, 14, 2860-2869. [CrossRef]

32. Pratap, S.; Nayak, A.; Kumar, A.; Cheikhrouhou, N.; Tiwari, M.K. An Integrated Decision Support System for Berth and Ship Unloader Allocation in Bulk Material Handling port. Comput. Ind. Eng. 2016, 106, 386-399. [CrossRef]

33. Pratap, S.; Nayak, A.; Cheikhrouhou, N.; Tiwari, M.K. Decision Support System for Discrete Robust Berth Allocation. IFAC-PapersOnLine 2015, 48, 875-880. [CrossRef]

34. Stojakovic, M.; Twrdy, E. A decision support tool for container terminal optimization within the berth subsystem. Transport 2015, 31, 29-40. [CrossRef]

35. Ursavas, E. Priority control of berth allocation problem in container terminals. Ann. Oper. Res. 2015, 1-20. [CrossRef]

36. Wang, F.; Lim, A. A stochastic beam search for the berth allocation problem. Decis. Support Syst. 2007, 42, 2186-2196. [CrossRef]

37. Oz, D.; Aksakalli, V.; Alkaya, A.F.; Aydogdu, V. An anchorage planning strategy with safety and utilization considerations. Comput. Oper. Res. 2015, 62, 12-22. [CrossRef]

38. Stelzenmüller, V.; Gimpel, A.; Gopnik, M.; Gee, K. Aquaculture Site-Selection and Marine Spatial Planning: The Roles of GIS-Based Tools and Models. In Aquaculture Perspective of Multi-Use Sites in the Open Ocean; Springer: Berlin, Germany, 2017; pp. 131-148. 
39. Yuan, L.; Changqing, L.; Yuebin, W.; Xiaoping, G.; Tao, X.; Reti, H.; Xiaohui, W.; Xiaowei, Z. Multi-criteria evaluation method for site selection of industrial wastewater discharge in coastal regions. J. Clean. Prod. 2017, 161, 1143-1152. [CrossRef]

40. Vasileioua, M.; Loukogeorgakia, E.; Vagionab, G.D. GIS-based multi-criteria decision analysis for site selection of hybrid offshore wind and wave energy systems in Greece. Renew. Sustain. Energy Rev. 2017, 73, 745-757. [CrossRef]

41. Jajac, N.; Knezic, S.; Marovic, I. Decision Support System to Urban Infrastructure Maintenance Management. Organ. Technol. Manag. Constr. 2009, 1, 72-79.

42. Saaty, T.L. The Analytic Hierarchy Process; McGraw-Hill International: New York, NY, USA, 1980.

43. Saaty, T.L. Decision making with the analytic hierarchy process. Int. J. Serv. Sci. 2008, 1, 83-98. [CrossRef]

44. Brans, J.P.; Mareschal, B.; Vincke, P.H. PROMETHEE-A New Family of Outranking Methods in Multicriteria Analysis; Operational Research IFORS 84; Brans, J.P., Ed.; Palgrave Macmillan UK: Amsterdam, The Netherlands, 1984; pp. 477-490.

45. Brans, J.P.; Vincke, P.H. A preference ranking organization method, the PROMETHEE method for MCDM. Manag. Sci. 1985, 31, 647-656. [CrossRef]

46. Brans, J.P.; Mareschal, B. Promethee-V-MCDM problems with segmentation constraints. Inf. Syst. Oper. Res. 1992, 30, 85-96. [CrossRef]

47. Brans, J.P.; De Smet, Y. PROMETHEE methods. In Multiple Criteria Decision Analysis; Springer: New York, NY, USA, 2005.

48. Jajac, N.; Rogulj, K.; Radnic, J. Selection of the Method for Rehabilitation of Historic Bridges-A Decision Support Concept for the Planning of Rehabilitation Projects. Int. J. Arch. Herit. 2016, 11, 261-277. [CrossRef]

49. Bitunjac, I.; Jajac, N.; Katavic, I. Decision support to sustainable management of bottom trawl fleet. Sustainability 2016, 8, 204. [CrossRef]

50. Hazır, Ö. A review of analytical models, approaches and decision support tools in project monitoring and control. Int. J. Proj. Manag. 2015, 33, 808-815. [CrossRef]

51. Kim, J.I.; Kim, J.; Fischer, M.; Orr, R. BIM-based decision-support method for master planning of sustainable large-scale developments. Autom. Constr. 2015, 58, 95-108. [CrossRef]

52. Taticchi, P.; Garengo, P.; Nudurupati, S.S.; Tonelli, F.; Pasqualino, R. A review of decision-support tools and performance measurement and sustainable supply chain management. Int. J. Prod. Res. 2014, 53, 6473-6494. [CrossRef]

53. Marović, I.; Hanak, T. Selection of adequate site location during early stages of construction project management: A multi-criteria decision analysis approach. Mater. Sci. Eng. 2017, 251, 1-8. [CrossRef]

54. Parthasarathy, S.; Sharma, S. Determining ERP customization choices using nominal group technique and analytical hierarchy process. Comput. Ind. Eng. 2014, 65, 1009-1017. [CrossRef]

55. Rogulj, K.; Jajac, N. Achieving a Construction Barrier-Free Environment: Decision Support to Policy Selection. J. Manag. Eng. 2018, 34, 04018020. [CrossRef]

56. Radman, Z.; Bubić, I.; Madiraca, M. Development Strategy Šolta Municipality Until 2020. Municipality of Šolta, 2015. Available online: http:/ / www.solta.hr/wp-content/uploads/2015/05/strategija_razvoje_solte_ travanj_2015.pdf (accessed on 13 September 2017).

57. Galasso, I. Analysis of the Spatial Potential of the Coastal Belt of the Split-Dalmatia County for the Purpose of Possible Activities Development of Anchorages and Mooring; Obala Ltd.: Split, Croatia, 2000.

58. Triantaphyllou, E.; Mann, S.H. Using the Analytic Hierarchy Process for decision making in engineering applications: Some challenges. Int. J. Ind. Eng. Appl. Pract. 1995, 2, 35-44.

59. Mareschal, B. Visual PROMETHEE. 2011. Available online: http://www.promethee-gaia.net/visualpromethee.html (accessed on 15 March 2017).

(C) 2018 by the authors. Licensee MDPI, Basel, Switzerland. This article is an open access article distributed under the terms and conditions of the Creative Commons Attribution (CC BY) license (http://creativecommons.org/licenses/by/4.0/). 